\title{
Targeting Sexual Stigma: The Hybrid Case Study of “Adam”
}

\author{
SARAH HOPE MANDEL ${ }^{\mathrm{a}, \mathrm{b}, \mathrm{c}}$ \\ ${ }^{a}$ Graduate School of Applied \& Professional Psychology, Rutgers-The State University of New Jersey \\ b \\ Correspondence regarding this article should be addressed to Sarah Hope Mandel, Graduate School of Applied \& \\ Professional Psychology, Rutgers-The State University of New Jersey, 152 Frelinghuysen Road, Piscataway, NJ \\ 08854 \\ Email: shmandel@gmail.com \\ C This article is a reformatted and edited version of my doctoral dissertation (Mandel, 2013).
}

\begin{abstract}
The purpose of this case study is to explore the effects of sexual stigma on mental health and corresponding therapy implications when working with lesbian, gay, and bisexual (LGB) clients during the coming-out process. This case study provides a literature review of sexual stigma and its consequences, describes multicultural considerations, and illustrates what are currently thought of as the best treatment practices when working with sexual minority clients. Treatment considerations are demonstrated via the hybrid case example of "Adam," who serves as a vivid portrayal of a psychotherapy client who struggles with research-consistent symptomatology and a crisis in identity formation. In addition to being informed by clinical examples in relevant psychological literature, Adam's composite case is assembled from actual psychotherapy cases. Demonstrating Adam's course of treatment provides an avenue for describing key clinical issues related to LGB mental health and the coming-out process. By adopting a qualitative, disciplined inquiry approach, I illustrate how, theoretically, treatment can be tailored to a potential client's unique psychological struggles within the context of historical, contextual, and cultural factors. Following a pragmatic case study research format (Fishman, 1999), Adam's case material is analyzed both qualitatively and quantitatively. It is proposed that the hybrid case of Adam demonstrates the potential for an integrative treatment approach, combining cognitivebehavioral, client-centered, and multicultural theories, in an effort to assist in the treatment of sexual minority patients who struggle with minority-stress, internalized homophobia, and identity formation concerns. The composite case study of Adam is designed to be used as a resource for therapists who seek to gain additional understanding of how to provide effective and affirmative treatment for LGB clients. The case study concludes with a critical discussion of the advantages and limitations of employing hybrid cases in lieu of actual ones.
\end{abstract}

Key words: sexual stigma; internalized homophobia; identity formation; LGB clients; LGB-affirmative therapy; multicultural theories; cognitive-behavioral therapy; client-centered therapy; hybrid case study; case study; clinical case study 


\section{CASE CONTEXT AND METHOD}

\section{The Rationale for Selecting this Particular Client for Study}

On September 19, 2010, a Rutgers University freshman named Tyler Clementi was broadcast on the internet during a sexual encounter with another young man; three days later, Tyler jumped to his death from the George Washington Bridge. The tragedy of Tyler's suicide amassed a media surge regarding the challenges facing gay adolescents. Questions still remain, however, concerning how to best serve the psychological needs of lesbian, gay, and bisexual (LGB) individuals, especially during the coming-out process.

Like other minorities, LGBs experience stigma, which is defined as the culturally shared knowledge that society views members of a group negatively (Herek, 2010). Stigma is a socially constructed negative evaluation regarding an enduring attribute (e.g. race, gender, sexuality, etc.) that results in the stigmatized group being labeled as undesirably different (Herek, 2010). Individuals who identify themselves as LGB are often victims of sexual stigma, and they endure "the negative regard, inferior status, and relative powerlessness that society collectively accords to any nonheterosexual behavior, identity, relationship, or community” (Herek, 2007, pp. 906907). Although "homophobia" has been culturally adopted as an appropriate term for sexual stigma or sexual prejudice, it is actually a misnomer. Sexually prejudiced individuals do not appear to "fear" LGBs as is implied by a "phobia;" instead, they react to nonheterosexuality with disgust and anger (Herek, 2004).

During my clinical training, I have treated multiple LGB clients who were struggling with their sexuality. The majority of the clients presented with symptoms research has found to be more common among LGB individuals; thus, for many of my patients, I conceptualized much of their distress as being related to minority-stress, internalized homophobia, and identity formation concerns. I found that adopting Persons' (2008) cognitive-behavioral theory as my guiding conception allowed me to create idiographic treatment plans in which cognitive restructuring, exposure techniques, mindfulness strategies, and my modeling of an affirming stance toward nonheterosexuality yielded psychological relief. In working with my LGB clients, I sought to uncover their internalized homophobia, challenge their negative views regarding their sexual orientation, and offer support and guidance towards entry into gay culture. The goal of treatment has been not only for my clients to tolerate their sexuality, but also to accept it.

In order to explore the effects of sexual stigma on mental health and corresponding therapy implications when working with LGB clients during the coming-out process, I have created a hybrid case example, which is an extension of a pragmatic case study. In addition to being informed by clinical examples in relevant psychological literature, this composite case is assembled from actual psychotherapy cases I have treated during my clinical training. The hybridized case will serve as a vivid portrayal of a psychotherapy client who struggles with research-consistent symptomatology and a crisis in identity formation. Presenting a course of treatment with this patient provides an avenue for describing key clinical issues related to LGB mental health. Additionally, by demonstrating my first-hand clinical experiences, this case study will build upon the existing knowledge base of best treatment practices that are currently found within the psychological literature. Since no single case can illustrate the heterogeneity of 
experiences for the sexual minority population, this hybrid case should not be interpreted as the only presentation of an LGB client during the coming-out process. However, by highlighting common themes that emerged in my psychotherapy treatment experiences, I hope to increase therapists' understanding of the effects of sexual-stigma on LGB clients, assist clinicians in their ability to formulate case conceptualizations for sexual minority patients, and improve the quality and effectiveness of psychotherapy services for this population.

The case study's structure follows the format of a traditional pragmatic case study, which includes: (i) a short description of the hybridized client; (ii) the case's theoretical guiding conception and associated literature review; (iii) a detailed assessment of the client's presenting problems, goals, strengths, and history; (iv) a case formulation and treatment plan; (v) a detailed description of the course of treatment; (vi) a review of therapy monitoring and the use of feedback; and (vii) a final quantitative and qualitative analysis of the therapy outcome (Fishman, 1999). I review literature on the effects of sexual stigma, explore multicultural considerations with LGB clients, and describe what are currently thought of as the best treatment practices when working with LGB clients. I adopt a qualitative, disciplined inquiry approach (Peterson, 1996), which allows treatment to be tailored to the client's unique psychological struggles within the context of historical, contextual, and cultural factors. As therapy progresses, reassessments allow for necessary "shifts" in focus according to the hybridized client's mental health needs.

I provide the reader with the results of fictionalized quantitative measures in order to concretely demonstrate the client's level of distress and internalized homophobia throughout the treatment. The hypothetical data also serves to emphasize the importance of incorporating ongoing assessment in treatment. I hope that including information regarding the utility of selfreport assessments will encourage therapists to use these specific quantitative measures with their own LGB clients, when appropriate. Although actual data is not presented, this study's data reflects general patterns I have observed within data I have collected across treatment with my LGB patients.

In this study I present a composite case of LGB clients, ages 18 through 34, for whom I have provided short- and long-term treatment in outpatient settings over my years as a doctorallevel graduate student. Although I have worked with lesbian and bisexual clients who have struggled with stigma-related symptomatology and internalized homophobia, a significant portion of my therapy experiences has focused on the treatment of gay men. Thus, the hybrid case presented in this study will focus on the experience of a young gay man who is undergoing the coming-out process.

The composite clinical case in this study, hereafter referred to by the pseudonym “Adam," is a 19-year-old college freshman who presents with symptoms of depression and substance abuse. Adam is beginning to navigate the coming-out process as a gay man, and is struggling with sexual stigma both within his external environment and internally.

\section{The Clinical Setting in Which the Case Took Place}

Adam's treatment took place in an urban university counseling center in the northeastern United States. The fee for treatment was reasonable and reflected the lowest possible tier of 
payment, which was standardized for all students within the university. While treating Adam, I was supervised by a licensed clinical psychologist with knowledge of cognitive-behavioral treatment for depression and substance use. In addition, supervision focused on diversity-related considerations specific to the coming-out process and the effects of stigma on mental health. Adam's treatment lasted for 40 weekly sessions, and was understood from the outset to be timelimited to approximately one year, given that my practicum at the university counseling center was a one-year placement.

\section{Sources of Data Available Concerning the Client}

No information was available to me prior to beginning treatment with Adam other than his responses to an initial phone intake at the Counseling Center. This was Adam's first experience with psychotherapy, and collateral information (e.g., from family members or university personnel) was not acquired.

\section{Confidentiality}

Given that Adam is not in fact a real person, but instead a composite of multiple individuals, the confidentiality of my previous patients will be protected. Additionally, in order to further protect my clients' identities, details of the hybridized case have also been fictionalized.

\section{THE CLIENT}

“Adam,” a 19-year-old, male, Caucasian, college freshman, sought treatment in order to address his symptoms of depression, declining academic performance, problematic use of marijuana, and significant distress regarding his being gay. He presented with symptoms of a Major Depressive Episode, as defined by the American Psychiatric Association's (2000) Diagnostic and Statistical Manual of Mental Disorders, Fourth Edition, Text Revision (DSM-IVTR), including a depressed mood, anhedonia, insomnia, decreased energy, difficulty concentrating, passive suicidal ideation, and feelings of guilt and worthlessness. He also met DSM-IV-TR criteria for Dysthymic Disorder, Early Onset, since on most days from age 13 on he had experienced a depressed mood, low self-esteem, and feelings of hopelessness. In addition, Adam met DSM-IV-TR criteria for Cannabis Dependence, Without Physiological Dependence, as he engaged in a maladaptive pattern of recurrent marijuana use, despite its negative impact on his mood and class attendance. He also used marijuana for longer periods than he had intended and had a persistent desire to better control his substance use behaviors. Adam was a likeable, intelligent young man who was burdened by significant negative beliefs about himself, the most salient of which were feelings of shame regarding his sexual orientation. This was Adam's first experience with individual therapy. Treatment spanned 40 sessions over the course of approximately ten months. 


\section{GUIDING CONCEPTION}

\section{Definition of Terms Related to Sexual Orientation}

Definitions of important concepts related to sexual orientation will be provided in order to clarify terms that are sometimes misunderstood. Sexual orientation refers to the sex (same or other) of the people to whom one feels sexually and emotionally attracted. Sexual behavior refers to the sexual activities (e.g., genital contact) in which an individual participates. While engaging in sexual behavior is a choice, research strongly suggests that one's sexual orientation is immutable (Ritter \& Terndrup, 2002). Sexual identity or sexual orientation identity refers to when individuals subjectively label and attach meaning to the experiences of their sexual desires, behavior, and romantic feelings. Importantly, sexual identity is not necessarily reflective of one’s sexual behavior (Dworkin, 2001; Igartua, 2012). Individuals may label their sexual identity as lesbian, gay, or bisexual. Additionally, there has been a recent movement toward expanding sexual orientation identity labels to reflect greater sexual fluidity, such as "queer," “mostly straight,” or "boidyke” (Cohen \& Savin-Williams, 2012). Same-sex sexual behavior, attractions, and orientation are "normal and positive variants of human sexuality" (American Psychological Association, 2009, p. 2).

Although transgendered individuals are often associated with the LGB population (e.g., represented as the " $\mathrm{T}$ " in LGBT), the term refers to individuals who experience their gender as conflicting with the sex they were assigned at birth. Given that gender identity and sexual orientation are concepts that require differing treatment competencies (Bidell, 2005), this study will focus on sexual orientation exclusively.

Finally, sexual minorities are defined as nonheterosexuals who experience oppression and lack privilege as compared to the heterosexual majority. Throughout this study, the term sexual minority will be used in addition to referring to lesbian, gay, and bisexual individuals via the acronym LGB.

\section{Sexual Stigma}

There are three categories of sexual stigma: i) enacted, ii) felt, and iii) internalized. Heterosexism, a term closely related to stigma, also negatively impacts the experience of LGB individuals.

Enacted stigma refers to an "overt behavioral expression of sexual stigma” and can involve criminal victimization, harassment, threats, the use of antigay epithets, shunning, and ostracism of LGB individuals (Herek, 2007, p. 908). Hate crimes toward sexual minorities are an extreme example of enacted stigma. According to Sue and Sue (2013), over 94\% of LGBT adults have experienced hate crime victimization.

Sexual minority individuals, however, need not be the victims of enacted stigma in order to experience the pernicious effects of stigma in their lives. Simply the knowledge that enacted stigma occurs can lead LGB individuals to experience felt stigma, i.e., a threatening sense that sexual stigma will be enacted in a particular circumstance (Herek, Gillis, \& Cogan, 2009). Felt stigma can motivate individuals to modify their behaviors and avoid specific contexts in order to 
maintain a subjective sense of safety. As a result, felt stigma can lead LGB individuals to withdraw from their social environment and thereby experience limited social support.

Internalized stigma, which is also known as internalized homophobia and self-stigma, refers to individuals' negative feelings regarding their nonheterosexuality (Herek, 2004). It indicates that the societal level of sexual stigma has been internalized into their self-concepts and values. Internalized stigma results in an internal conflict between what individuals think they should be (heterosexual) versus their actual experience of sexuality (nonheterosexual). Due to residence in a culture that promotes sexual stigma, many LGB individuals experience internalized stigma during their identity formation and thereafter throughout their lives (Herek, Cogan, Gillis, \& Glunt, 1997). The highest levels of internalized stigma have been found in men, the politically conservative, and the extremely religious (Herek et al., 2009).

Heterosexism refers to the structural level at which "society's institutions and ideological systems legitimate and perpetuate sexual stigma and the differentials in status and power that it creates” (Herek, 2007, p. 907). Heterosexism promotes two key notions that lead to the reduction in power for nonheterosexuals: (i) all individuals are assumed to be heterosexual (which leads LGB individuals to feel invisible in most social contexts) and (ii) when visible, nonheterosexual relationships and behaviors are viewed as abnormal and problematic (Herek, 2010). Language that promotes negative associations with sexual minorities, such as the commonly heard phrase "that's so gay," represents a form of heterosexism (Beckstead \& Israel, 2010). According to Herek et al. (1997), American culture is "pervaded" with heterosexism; society's institutions such as religion, law, and medicine have historically legitimized the inferior status of LGB individuals as compared to heterosexuals (p. 17).

Current manifestations of heterosexism in American culture include LGB individuals' (i) inability to file joint tax returns, (ii) not being granted sick leave from work if their partner is ill, (iii) inability to receive child custody if they are not the child's biological parent, and (iv) unequal marriage rights as compared to heterosexuals (Pizer, 2012). In addition, although antisodomy laws were declared unconstitutional by the U.S. Supreme Court in 2003 (i.e., Lawrence $v$. Texas), several states continue to perpetuate antisodomy laws within the states' legal codes. In Kansas, for example, law enforcement officers may charge same-sex couples who engage in oral or anal sex with a misdemeanor that officially carries a prison sentence of up to six months (Sulzberger, 2012).

\section{The History of Sexual Stigma}

Historically speaking, sexual orientation is a relatively recent construct. The word "homosexuality" was first introduced in 1868 by a Hungarian writer, and "heterosexuality" was coined thereafter (Herek, 2010). Despite Western society’s lack of terminology, starting as early as the sixth century, individuals who engaged in same-sex behavior were victims of scapegoating; they were blamed for natural disasters, including plagues and famines, and were punished by death in these times of crises (Fassinger, 1991). Punishment for same-sex behavior among women was outlined in a 1260 legal code, which included clitorectomies for first offenses and burning at the stake for additional same-sexual behaviors (Fassinger, 1991). 
Sexuality in the early nineteenth century in Western society was regarded quite differently as compared to modern times. In the 1800's, marriage, procreation, and securing wealth were considered the crux of a relationship. Love and lust were considered as "polar opposites... [n]ineteenth-century ideologists of eros imagined a crack in the world, with love on one side, and lust on the other" (Katz, 2001, p. 333). Sexual acts that did not result in procreation were deemed animalistic. In fact, in the nineteenth century the term sodomy encompassed any sexual act that did not involve vaginal intercourse between a husband and wife - meaning that same-sex sexual behaviors, masturbation, and pre- and extra-marital heterosexual affairs were regarded as repugnant. During this time, the extremely narrow definition of sexuality did not include "heterosexuality" or "homosexuality" (Katz, 2001).

In the late nineteenth century, the notion of sexual attraction began to gain credence. According to Herek (2010), the importance of attraction became increasingly widespread as psychiatry began to embrace sexuality (with the help of Sigmund Freud's conception of sexual behavior in the early 1900's). Love and sex, for the first time, were regarded as intimately related. Although during the early twentieth century heterosexuality was viewed as the healthiest expression of love and sexuality, Freud did not regard same-sex behavior as a form of mental illness. In fact, challenging previous notions of sexuality, he argued that humans were inherently bisexual. For example, Freud responded by letter to a woman seeking advice about her gay son, writing that "it is nothing to be ashamed of, no vice, no degradation, it cannot be classified as an illness” (Herek, 2010, p. 694).

In the 1940s, however, Freud's view of sexuality was no longer embraced by American psychoanalysts. Instead, it was posited that all human beings were naturally heterosexual and that any nonheterosexual behavior was indicative of a phobic response to members of the opposite-sex (Herek, 2010). Being gay had become a sickness, and in fact, the psychiatry and psychology field played a fundamental role in legitimatizing and thereafter perpetuating heterosexism by listing "homosexuality" as a mental disorder in the Diagnostic and Statistical Manual of Mental Disorders (DSM). Conversion (a.k.a. reparative) "therapies” were touted by psychologists as "cures" for sexual minorities; these treatments sometimes included aversive strategies such as electric shocks to the genitals or nausea-inducing drugs (Herek, 2010).

In the late 1960s, the psychology field began to alter its stance with the help of Alfred Kinsey’s (1953) sexuality research and Evelyn Hooker’s (1957) Rorschach, Thematic Apperception Test, and Make-A-Picture-Story Test study. Both researchers determined that being gay was not associated with pathology (Herek, 2010). In 1973, the empirical evidence and shifting cultural views toward "homosexuality" led the American Psychiatric Association to remove it as a mental disorder from the DSM. The excising of "homosexuality" from the DSM and the field's change in focus from "transforming” or "curing” sexual minorities to actively supporting their identity formation served to decrease heterosexism. The American Psychological Association is now adamant in its view that LGB conversion "treatments" are completely inappropriate and carry the risk of harming clients (American Psychological Association, 2009).

It is important to note that sexual stigma is socially constructed; the history of sexual stigma described above reflects recent European and mainstream American views toward 
nonheterosexuality. For example, before Native Americans were forced to acculturate into a European colonial context, LGB Native Americans were perceived as assets within their communities (Balsam, Huang, Fieland, Simoni, \& Walters, 2004). An individual with a nonheterosexual orientation and/or who embodied both feminine and masculine traits was known as "two-spirited." Within their original cultural context, two-spirits were viewed with respect and were often regarded as honorable and sacred (Balsam et al., 2004; Meyer, 2010). Today, however, the majority of two-spirits encounter sexual stigma and oppression from mainstream American society and from their own tribes.

\section{LGB Mental Health}

The association between stress and physical and mental health is well established (Lewis, Derlega, Griffin, \& Krowinski, 2003). For the LGB community, however, it is important to recognize that there is another type of stress in addition to that generated by life events. Called gay-related or minority stress, it results from belonging to a group that has been culturally categorized as inferior, and leads to social prejudice and discrimination (Lewis et al., 2003). Despite the fact that LGB individuals experience prejudice in Western society, many demonstrate resilience and effective coping strategies in the face of adversity and do not evidence mental health disorders (Schneider, Brown, \& Glassgold, 2002; Sue \& Sue, 2013). Yet for others, the consequences of living in an environment imbued with discrimination negatively affects psychological well-being and adaptation.

Indeed, there is increasing awareness that LGB adolescents and adults may be at higher risk for psychological disorders due to minority-stress and social stigma (Cochran, Sullivan, \& Mays, 2003). Coker, Austin, and Schuster (2010) found that there are "substantially more health risk behaviors and worse health outcomes for LGB youth compared to heterosexual youth" (p. 458). Furthermore, many LGB individuals, particularly those in the earliest stages of gayidentity development, may have few outlets of social support due to society's rejection of nonheterosexuality; this lack of support may only serve to magnify the effects of minority-stress (Coker et al., 2010).

Researchers' finding that social stress can influence the development of mental disorders holds true in particular for affective disorders (Cochran et al., 2003). LGB individuals who experience prejudice based upon their sexual orientation are at an increased risk of depression, especially if they remain silent about their experiences (Sue \& Sue, 2013). Lewis et al. (2003) found that gay-related stress and life stress were both significantly and positively associated with depressive symptoms; subjects who indicated higher stigma awareness and higher stigma-related stress reported greater depressive symptoms. In Cochran et al.'s (2003) study, gay and bisexual men were three times more likely to meet criteria for major depressive disorder compared to heterosexual men. Additionally, almost $20 \%$ of the study's gay and bisexual men were comorbid for two or more mental disorders (Cochran et al., 2003).

National and state representative surveys have demonstrated that LGB individuals evidence higher rates of substance use as compared to heterosexuals. In one recent metaanalysis, LGB individuals were three times more likely to use substances as compared to nonLGB individuals across studies (Coker et al., 2010). LGB individuals may be using alcohol or 
drugs to self-medicate their depression and/or attempt to numb their pain from feeling "different" (Ritter \& Terndrup, 2002). Rosario, Schrimshaw, and Hunter (2009) found that the amount of rejecting reactions to LGB's disclosure of their sexual identity was associated with current and future marijuana, cigarette, and alcohol use. On the other hand, reactions of acceptance from others to the coming out process protected LGB youths from alcohol use. Supporting the minority-stress model, Rosario et al.'s (2009) research suggests that the stress of rejection may lead to substance use among LGB youths.

One tool used by researchers to investigate LGB individuals’ internalization of society’s denigration of sexual minorities is the Internalized Homophobia Scale (Herek et al., 1997). According to Herek et al. (2009), internalized homophobia (a.k.a., internalized stigma) significantly contributes to psychological distress and well-being. Herek et al. (2009) found that the internalized homophobia/psychological distress relationship was mediated by self-esteem, such that higher levels of internalized homophobia resulted in lower self-esteem, which in turn led to higher psychological distress and reduced positive affect. In addition, higher levels of internalized homophobia are associated with reduced openness about sexual orientation, less sense of belonging within the LGB community, and difficulties related to intimacy, relationship quality, social support, physical health, and career development (American Psychological Association, 2012; Herek et al., 1997). Gay and bisexual men score significantly higher than lesbian and bisexual women on the internalized homophobia measure (Herek et al., 1997). This finding is not entirely surprising given that gay men are more stigmatized than lesbian or bisexual women (Herek et al., 1997; Martell, Safren, \& Prince, 2004). Perhaps the greater rate of internalized homophobia among gay men is directly related to American culture's increased distaste toward gay men, which then becomes internalized by this population and evidenced on the internalized homophobia scales.

\section{Multicultural Considerations}

Although multiculturally-informed treatment was originally intended for therapy with African American, Asian American, Native American, and Hispanic and Latino populations (Sue, Arredondo, \& McDavis, 1992), the field of psychology has since broadened its definition of multiculturalism to encompass diversity related to gender, religion, disability, socioeconomic status, and sexual orientation (Mio, Barker-Hackett, \& Tumambing, 2009; Sue \& Sue, 2013). Since there are significant commonalities between the experiences of sexual and ethnic minority populations, multicultural treatment can be applied to LGB individuals. For example, individuals in both populations undergo a similar process of identity development (Pope, 1995). In addition, sexual minority and ethnic minority individuals experience stereotyping and stigmatization (Israel \& Selvidge, 2003). A multicultural orientation seeks to acknowledge and treat the effects of multiple "isms" such as racism, sexism, and heterosexism; these "isms" are the deleterious byproducts of oppression in which one cultural group is advantaged over another (Fassinger \& Richie, 1997).

Even though there are overlapping areas of experience, important distinctions exist between ethnic and sexual minority populations. Unlike ethnic minority individuals, the majority of LGB individuals are raised in communities and families whose members do not share their sexual minority status (Israel \& Selvidge, 2003). Furthermore, ethnic minority status is 
frequently identified more easily than that of sexual orientation (i.e., LGBs are the "invisible minority”) and also, sexual orientation is focused on sexuality, which is often a controversial topic for many people (Bowers \& Bieschke, 2005; Israel \& Selvidge, 2003). Despite these distinctions, a multicultural orientation provides a valuable framework when working with sexual minority clients (Israel \& Selvidge, 2003).

Attending to one's attitudes, knowledge, and skills is central to a culturally competent treatment approach (Sue et al., 1992). First, therapists must strive to be aware of their own personal values, biases, and assumptions, and how these may impact the therapeutic relationship and perception of the client (Sue, 2006). Second, therapists must educate themselves regarding a client's culture, particularly when it differs from their own, and seek knowledge of social and political factors related to a client's specific cultural identity (Fassinger \& Richie, 1997). Third, therapists must acquire the ability to provide sensitive and relevant intervention techniques which are consistent with clients' cultural values (Sue at al., 1992). Becoming culturally competent is an active, aspirational process that should continue throughout one's professional career (Sue \& Sue, 2013).

Sue et al.'s (1992) culturally competent framework can be readily adapted to meet the needs of LGB clients. Therapists should seek to become aware of attitudes or preconceived notions that they hold toward sexual minorities, and understand how discrimination and stereotyping have affected their LGB patients. Indeed, research suggests that many therapists hold negative biases toward LGB clients and are prone to overpathologizing sexual minorities (Bowers \& Bieschke, 2005). In the case of heterosexual therapists, consideration of how they directly or indirectly benefit from heterosexism will be helpful in uncovering awareness of privilege and oppression, and how these factors may influence the work in therapy. Therapists working with sexual minority clients should become knowledgeable regarding the sociopolitical history of LGBs, including lack of civil rights and fear of victimization by enacted stigma (Pope, 1995). Psychologists should also seek out clinical training with sexual minorities and familiarize themselves with LGB-related clinical research.

Therapists, however, should also be aware of sexual minority factors that differ from the standard multicultural treatment model. Feeling invisible, isolated, and/or pressured into a life of secrecy (Fassinger \& Richie, 1997; Pope, 1995), the coming-out process, and family of origin issues (e.g., fear of ostracism) differ for LGBs versus other minority populations. Although these issues give rise to potentially significant treatment implications, culturally competent therapists will also recognize when sexual orientation should not be the primary focus in treatment (Israel \& Selvidge, 2003; Matthews, 2010; Pachankis \& Goldfried, 2004; Ritter \& Terndrup, 2002).

When working with LGB individuals, it is important to consider the salience of clients' multiple identities and their inherent interaction. Hays’ (1996) “ADRESSING” model is a particularly useful acronym to which therapists can refer in order to increase awareness of cultural factors. The ADRESSING model encompasses the consideration of Age, Disability, Religion, Ethnicity, Social status, Sexual orientation, Indigenous heritage, National origin, and Gender (Hays, 1996). Use of this model can increase therapists' understanding of within-group differences for particular minority groups and diminish the risk of generalizing. Therapists 
should explore how clients' idiosyncratic cultural contexts impact the meaning LGB clients attach to their sexual orientation (Hays, 1996). For example, the presenting problems of a gay man raised in a rural, politically conservative, Catholic household may differ dramatically from those of a gay man raised in an urban, politically liberal, atheist household.

\section{LGB Treatment Implications}

What can therapists do to help clients cope with minority-stress and reduce the likelihood that clients will experience psychological distress? Research suggests that a tailored, integrative treatment approach combining client-centered, affirmative, and cognitive-behavioral interventions can help to alleviate potential mental health problems that are unique to the LGB population, such as isolation, feeling invisible, lack of role models, discrimination, and internalized homophobia.

LGB patients report positive outcomes when provided with a client-centered treatment approach, in which the therapist (i) conveys unconditional positive regard and empathy, (ii) demonstrates openness and acceptance of the client's important values and concerns, and (iii) encourages the client’s positive self-concept (American Psychological Association, 2009). Unconditional positive regard is especially warranted with this population in order to demonstrate respect for a client's sexual orientation, lifestyle, attitudes, beliefs, and integrity (Pachankis \& Goldfried, 2004).

In an effort to provide LGB patients with an effective form of psychotherapy that attends to diversity-related factors such as sexual stigma, an affirmative model of therapy was created for use with sexual minority clients (American Psychological Association, 2009; Fassinger, 1991). Affirmative treatment is supportive of clients' identity development, regardless of how clients choose to identify or express their sexual orientation (American Psychological Association, 2009). There are four central components to affirmative treatment: creating a sense of safety in the therapy environment; supporting open dialogues regarding sexuality; exploring the meanings clients attach to their sexuality; and demonstrating the ability to convey understanding of patients via validation and awareness (American Psychological Association, 2012). A therapist must also acknowledge the impact of stigma on mental health. For example, a "counterhomophobic" therapy stance in which a therapist conveys to a sexual minority client that being LGB is a nonissue (in a misguided effort to demonstrate a lack of bias) belittles the real and pervasive effects of stigma; thereafter, this patient will likely feel uncomfortable voicing the difficulties associated with being marginalized (McWilliams, 1999, p. 61). Through interventions such as normalization, psychoeducation, exploration, reevaluation, and integration, affirmative treatment seeks to empower clients by broadening their perspectives, increasing self-efficacy, and replacing negative internalized beliefs with feelings of worth and belongingness (Beckstead \& Israel, 2010).

Given that sexual orientation is not as readily identifiable as are some ethnic identities, therapists must create LGB-affirming environments for all of their clients (Israel \& Selvidge, 2003). For example, using neutral language on intake forms by including the word partnered in addition to married, single, or divorced reduces heterosexist bias (Israel \& Selvidge, 2003; Sue \& Sue, 2013). Additionally, assuming heterosexuality unless a client indicates otherwise 
perpetuates heterosexism (Garnets, Hancock, Cochran, Goodchilds, \& Peplau, 1991); therapists must avoid assumptions based upon a client's marital status or sexual behavior (Matthews, 2010; Pachankis \& Goldfried, 2004). Therapists should also display "safe zone” signs such as a rainbow or pink triangle to convey both a sense of safety and an affirmative therapeutic climate (Israel \& Selvidge, 2003; Matthews, 2010).

There is an emerging research base which suggests that cognitive-behavioral therapy (CBT) is effective with minority populations (Hays, 2009); therefore, the addition of sexual minority considerations to a CBT framework may provide clinicians with an effective affirmative treatment (Pachankis \& Goldfried, 2004; Safren, Hollander, Hart, \& Heimberg, 2001). Indeed, LGB adults report that they benefit from client-centered, multicultural, evidencebased treatment approaches that emphasize (i) assessment, (ii) support and acceptance, (iii) coping skills, (iv) social support, and (v) identity development (American Psychological Association, 2009). Additionally, given that depressive disorders are more prevalent among the LGB population (Cochran et al., 2003), CBT may be particularly beneficial as a sexual minority treatment approach since it has shown to be effective in the treatment of depression (Martell et al., 2004).

Martell et al.'s (2004) Cognitive Behavioral Therapies with Lesbian, Gay, and Bisexual Clients provides readers with an understanding of how to utilize a culturally sensitive, affirmative CBT treatment approach with sexual minority clients, particularly those who suffer from depression, anxiety, obsessive-compulsive disorder, and posttraumatic stress disorder. According to Martell et al. (2004), CBT is especially well-suited to address the specific burdens faced by the LGB population because individualized treatment plans and case conceptualizations focus on the unique client and environmental impacts (e.g., heterosexism) on behavior. For example, most LGBs are raised by people who identify as heterosexual, who often assume that their offspring will also be heterosexual. Therefore, LGB individuals are often raised in invalidating environments, which can lead to the origin of negative core beliefs (e.g., "I'm abnormal”), isolative behaviors, and/or the onset of depressive disorders (Martell et al., 2004). CBT can help LGB patients (i) challenge and evaluate their negative assumptions, (ii) teach clients mindfulness interventions, which can allow them to accept their thoughts as simply thoughts and not truths, and (iii) learn behavioral activation skills in order to engage with a supportive community (Martell et al., 2004).

Levounis, Drescher, and Barber's (2012) The LGBT Casebook presents readers with common problems that LGBT individuals face in their everyday living, such as bullying, family rejection, discrimination, internalized homophobia, and issues related to identity development. Demonstrating an integrative, affirmative treatment approach, Levounis et al. (2012) describe best treatment practices via case study vignettes of LGBT clients struggling with a range of problems, including Substance Dependence, Major Depressive Disorder, Dysthymic Disorder, and Identity Problems, to name a few. Much like the format of The LGBT Casebook, this article will also provide readers with a case study format (albeit focusing in depth on one client) in order to concretely demonstrate affirmative, integrative treatment interventions with a sexual minority client. 
Given that many sexual minority individuals contend with unique burdens such as internalized homophobia, identity development concerns, issues related to coming out, and difficulty accessing social support, clinicians should seek knowledge regarding each of these areas. Specific treatment interventions have been proposed which are geared toward the resolution of each of these potential problems.

Various clinical interventions may be helpful in addressing the "double whammy" of both external and internalized oppression (Fassinger \& Richie, 1997, p. 85). As a result of developing within a context inundated with antigay attitudes, many LGBs have difficulty acknowledging, to themselves and others, their same-sex feelings and attractions (Drescher, 2012). In the case example of "Felix," Glassgold (2009) describes her gay client who experienced panic attacks due to self-stigma and fear of disclosing his sexuality, highlighting the importance of offering LGB clients a forum in which to gradually expose themselves to what they fear: their sexuality. By creating a safe, affirmative environment, clinicians can help these clients explore their sexual and romantic longings. Additionally, increasing LGB clients' awareness of their internalized homophobia is essential; this self-knowledge can be aided by asking about their (i) coming-out experiences, (ii) experiences with oppression in their family, school, religious institution, and workplace, and (iii) views of sexual minorities (Sue \& Sue, 2013). Once a client's internalized homophobia is uncovered, clinicians can help the patient identify and correct cognitive distortions, increase coping skills, and provide guidance to augment social support (Sue \& Sue, 2013). These treatment interventions seek to replace internalized heterosexist attitudes with affirming messages regarding LGB clients' evolving identities (Sue \& Sue, 2013).

Although multiple stage models of identity development exist, perhaps the most predominant is Cass's (1979) lesbian and gay identity development model of (i) identity confusion, (ii) identity comparison, (iii) identity tolerance, (iv) identity acceptance, (v) identity pride, and (vi) identity synthesis. In identity confusion, individuals experience feelings of distress as they begin to consciously recognize that they may be gay or lesbian (Ritter \& Terndrup, 2002). Identity comparison is characterized by feeling alienated from others due to the possibility of being gay or lesbian (Fassinger, 1991; Ritter \& Terndrup, 2002). In identity tolerance, individuals acknowledge that they are likely gay or lesbian and may begin to seek out contact with the gay community (Fassinger, 1991; Ritter \& Terndrup, 2002). Identity acceptance is characterized by initiating additional and ongoing contacts with the gay community and becoming accepting of one’s gay or lesbian self-image (Fassinger, 1991; Ritter \& Terndrup, 2002). In identity pride, an individual immerses his or herself in the gay subculture, becomes an activist for gay rights, and rejects nongay people and values (Fassinger, 1991; Ritter \& Terndrup, 2002). Finally, identity synthesis is marked by the incorporation of sexual orientation as only one aspect of an integrated identity. Individuals also acknowledge similarities between themselves and heterosexuals and recognize differences between themselves and other sexual minorities (Fassinger, 1991; Ritter \& Terndrup, 2002).

Cass’s (1979) identity development model has been criticized for its (i) linear assumption of stage progression, (ii) the necessity of proceeding through a public and political identity in order to reach the most valued (final) stage of identity development, and (iii) insensitivity to other diversity-related identities and their interaction with sexual orientation, such as race, 
ethnicity, age, socioeconomic status, and religion (Fassinger, 1991). Although clinicians should therefore apply gay identity development theories with caution and assess whether the model fits with a particular client's presentation (Martell et al., 2004), incorporating identity development considerations within a client's case conceptualization may aid clinicians in selecting appropriate treatment interventions (Ritter \& Terndrup, 2002).

The decision to come out can be a period of great distress and is often accompanied by depression and/or anxiety (Martell et al., 2004). During this process, sexual minority individuals continually confront the possibility of discrimination and often navigate their disclosures within the context of inadequate social support and few (or no) role models (Fassinger, 1991). Although many mental health professions hold that appropriate self-disclosure can facilitate psychological health (Cohen \& Savin-Williams, 2012), sexual minority individuals also need to weigh the safety of their disclosure and avoid coming-out indiscriminately (Drescher, 2012). In addition, coming out is a continuous process as LGBs must decide daily, perhaps for the rest of their lives, whether to reveal their sexual orientation to new acquaintances (Drescher, 2012). Therapists can help clients identify whether and whom to come out to, and to practice said disclosures via role playing exercises (Fassinger \& Richie, 1997).

As soon as clients become amenable to seeking support beyond individual therapy, clinicians should assist them in developing ties to the gay community in order to create a network of support (Israel \& Selvidge, 2003). Sexual minorities tend to experience improved psychological functioning as a result of engagement with the LGB community (American Psychological Association, 2012), and the most important variable in the establishment of a positive gay identity is accessing other sexual minority individuals (Ritter \& Terndrup, 2002). Therefore, therapists must familiarize themselves with relevant community resources when working with LGB clients (American Psychological Association, 2012).

Furthermore, Dooley's (2009) research found that a mentor relationship can be beneficial to LGB individuals as they begin the coming-out process and start to navigate their sexual identity. These mentors were seen as "cultural broker[s]" who were able to "operate in the subculture as well as the dominant society" (Dooley, 2009, p. 25). The mentor was described as a role model or guide who had familiarity with gay life and was able to ease the newly-out LGB individual into accepting his or her identity. Mentors offered a positive coping strategy and armed LGB individuals with the capacity to better deal with stigma.

Although this literature review focuses on mental health and treatment implications when working with LGB clients, it is important to note that the experiences of lesbian, gay, and bisexual people are not always overlapping. For example, individuals who identify as bisexual may struggle with significant difficulty establishing a sense of belonging since they are often confronted with discrimination from both the heterosexual and gay community (Dworkin, 2001). Furthermore, bisexual identity formation is not a linear process with a fixed outcome and is oftentimes marked by “continued uncertainty” (Ritter \& Terndrup, 2002, p. 110), which differs dramatically from the models of gay and lesbian identity development (Ritter \& Terndrup, 2002). The case study of Adam will highlight the experiences of a gay male rather than addressing important clinical issues that may arise when providing therapy to a lesbian or bisexual individual. 
The psychological literature points to the benefits of client-centered, affirmative, and cognitive-behavioral treatment with sexual minority clients. In hopes of providing my client, Adam, with the most effective and empowering course of therapy, the guiding conception of his treatment integrated the approaches delineated above with special attention focused on the unique experiences of sexual minority individuals. Given that Adam presented with substance abuse problems in addition to depression, harm reduction and motivational interviewing interventions were also included.

\section{ASSESSMENT OF THE CLIENT'S PRESENTING PROBLEMS, GOALS, STRENGTHS, AND HISTORY OF PRESENTING PROBLEMS}

Adam presented for treatment to address his symptoms of depression, which he reported began at age 13. Despite his history of experiencing an "on and off" depressed mood over the previous five years, Adam was able to excel in high school and gain entry into a prestigious university. Since starting college, however, his depressive symptoms had intensified and were beginning to interfere with his functioning. His depression increased to the extent that he was beginning to withdraw from his friends.

Adam had been smoking marijuana regularly for the previous two years. He typically smoked one to two joints every Friday and Saturday with his friends. Since beginning college, however, Adam had increased his marijuana intake, and began smoking during the weekday evenings while alone or with several of his dorm-mates. He started to have difficulty attending his morning classes because he woke up feeling “drowsy.” He would then lie in bed and berate himself for having used marijuana the night before and would remain in bed because he thought to himself, "I won't be able to absorb anything in class if I go like this." Adam was beginning to realize that in addition to negatively impacting his class attendance, his marijuana use was contributing to his depression because his mood suffered as he came down from the high. Furthermore, although he had the desire to cut down his marijuana use, he was ambivalent about reducing his smoking because he enjoyed the initial high.

Prior to our first session, I was provided with a copy of Adam's phone intake, which indicated that he had endorsed a heterosexual orientation. Toward the end of our in-person intake session, however, Adam stated that he was in fact gay (for more on this process, see "Course of Treatment", below). He shared that he had endorsed a heterosexual orientation to the phone intake screener because he felt uncomfortable, and had not "come out” to anyone before. Adam started to recognize his same-sex attractions at age 13, and expended great effort to conceal them from others. Yet he had hoped to come out when he began college (which was located a far distance from his hometown) and begin exploring his sexuality more openly. Adam said that the reality of coming out had become "overwhelming" to him, "flooding" him with negative thoughts and feelings, and he had not been able to proceed according to his original plan.

\section{Quantitative Assessment}

Starting from the beginning of treatment, Adam completed three psychometrically sound quantitative measures on a bi-weekly basis, which he filled out prior to our sessions. I chose to 
administer the measures every-other week because filling out multiple forms can be time consuming for patients. I have found that giving measures bi-weekly provides me with a sense of how a patient is faring and whether the treatment is on track. The initial scores on each of the measures were consistent with Adam's qualitative presentation. Ongoing results of these measures were discussed throughout the course of therapy and helped to guide treatment.

Given that Adam was experiencing symptoms of depression, the Beck Depression Inventory - Second Version (BDI-II) was administered. The BDI-II is comprised of 21 items (each of which can be scored from 0 to 3 points), with a higher score indicating more severe depressive symptoms (Beck, Steer, \& Brown, 1996). A score of 0-13 (inclusive) is indicative of minimal depression; 14-19, mild depression; 20-28, moderate depression; and 29-63, severe depression (Beck et al., 1996). Adam received a BDI-II score of 27 at the start of treatment, indicating that he was experiencing moderate symptoms of depression. Adam's scores on the BDI-II indicated whether his depressive symptoms were increasing, remaining stable, or abating; his BDI-II scores can be seen in Table 1.

In order to assess Adam's general distress level, his satisfaction regarding interpersonal relationships, and his school adjustment, the Outcome Questionnaire - 45 (OQ-45) was administered. The OQ-45 is a 45-item, self-report measure that has a total score and three subscale scores: Symptom Distress, Interpersonal Relations, and Social Role (Lambert, Burlingame, Umphress, Hansen, Vermeersch, Clouse, \& Yanchar, 1996). Adam’s OQ-45 results are presented in Table 2. At the start of treatment, all of Adam's scores on the OQ-45 were above clinical cut-off, indicating distress across multiple domains, including school and social life.

Given that research has indicated that internalized homophobia can lead to psychological distress (American Psychological Association, 2012; Herek et al., 1997), Adam’s level of internalized homophobia was assessed with the Internalized Homophobia Scale (IHP) (Meyer, 1995). The IHP is comprised of 9 items, each of which is scored on a Likert-type scale from 1 (disagree strongly) to 5 (agree strongly) (Herek et al., 1997). Queries for men include: "I wish I weren’t homosexual/bisexual," "I feel that being homosexual/bisexual is a personal shortcoming for me,” and "I have tried to become more sexually attracted to women.” Scores range from 9 (no internalized homophobia) to 45 (extreme internalized homophobia). At the start of treatment, Adam evidenced high internalized homophobia with a score of 40 . His IHP scores can be seen in Table 3.

\section{Relevant Personal History}

Adam grew up with his father, mother, and younger sister in a small city in the Midwestern United States. His father placed a strong emphasis on academic achievement, and Adam often felt pressure to receive straight A's and be the "perfect child." His father repeatedly conveyed the importance of Adam representing his family positively by being both successful and well-liked by the community. The client described a strained relationship with his father, whom he found to be stoic and difficult to connect with on an emotional level. He had a closer relationship with both his mother and sister, from whom he felt warmth and support. Adam described his sister, only one-and-a-half years younger than he, as his "best friend." She 
embodied characteristics that he admired, such as creativity and the courage to be outspoken, even with their strict father.

Adam was raised Catholic and attended church regularly with his family as he grew up. Although he found comfort in the church's teachings and community, once Adam started to recognize his same-sex attractions, he began to feel alienated due to his church's overt rejection of same-sex behavior. During his teenage years he began to avoid attending church, and found that using schoolwork as an excuse to stay home on Sundays was often met with relatively little resistance from his parents.

After Adam's sophomore year of high school, he worked as a counselor at a sleep-away camp. Adam described this summer as "life altering" due to having his first gay sexual encounter with another male counselor. He recounted a history of having girlfriends, in which sexual activity was "nice." Yet his experience of being intimate with a man was significantly more arousing and made him realize that he was in fact gay. Although the relationship was mostly focused on sex, Adam also felt an emotional connection with this young man. However, they both kept their relationship secret for fear of being ostracized. At the end of the summer, they agreed to end their relationship as they lived a distance away from one another in separate states. Despite feeling saddened by the loss of the relationship, Adam also felt "relieved" because he feared that had the relationship continued, his family and community may have discovered that he was gay. Once Adam began applying to colleges, he decided to choose a university in a gay-friendly city in which he could more comfortably come out.

\section{Presentation at the Beginning of Therapy}

This was Adam's first experience in therapy. At the start of working together, Adam presented with depressed affect and a sense of hopelessness about the future. He shared many negative thoughts about himself, including that he was "abnormal” because he was gay and would "never fit in” with anyone, anywhere. Adam also voiced disappointment in himself because although he had planned to come out once he began college, he ended up not having the "courage" to do so. Using marijuana helped to reduce his feelings of hopelessness and distracted him from his negative thoughts in the short term. However, Adam acknowledged that his recent increase in smoking was making him feel more depressed and was contributing to him feeling too "sluggish" to attend his classes or complete his homework. Despite his recurring desire to gain control over his substance use, Adam continued to smoke regularly. He expressed disappointment in himself for working "so hard" to get himself into a reputable college, only to "throw away" his education once arriving there. Whereas working on class assignments often served as a distraction from his depressed mood throughout high school, he was now having difficulty concentrating on school tasks. He was motivated to seek out therapy out of fear that his grades were going to be negatively affected by his absences and his difficulty completing his classwork.

From the start of treatment, Adam presented as ingratiating and highly invested in my liking him. For example, he would apologize for saying he felt hopeless and like a failure, adding that he did not want to "burden" me and hoped that I did not find him to be "annoying." After I educated Adam about the therapy process, he appeared to find some relief in the fact that 
we were in a safe space where he could share any thoughts and feelings, and that I could handle what he brought my way. He said that despite feeling sad much of the time, he had been "programmed to wear a happy face" and was uncomfortable sharing his true feelings with people.

\section{Diagnosis (Table 4)}

As shown in Table 4, Adam met DSM-IV-TR criteria for Major Depressive Disorder, Moderate, Single Episode. For the previous three weeks, he had been struggling with a depressed mood, most of the day, nearly every day. In addition, he experienced anhedonia, insomnia, decreased energy, difficulty concentrating, and feelings of guilt and worthlessness. Adam also endorsed passive suicidal ideation ("death would be a relief”) but denied a plan or intent to harm himself. Adam's depression increased to the extent that he found it difficult to complete daily life tasks, such as interacting with friends.

Adam also met DSM-IV-TR criteria for Dysthymic Disorder, Early Onset (see Table 4), since on most days from age 13 on he had experienced a depressed mood for most of the day, low self-esteem, and feelings of hopelessness. Although his mood improved during the summer when he worked as a camp counselor, the Dysthmia reemerged upon his return home after being away for almost two months. Since Adam presented with a Major Depressive Episode superimposed upon Dysthymic Disorder from the start of treatment, he met criteria for double depression.

Adam met DSM-IV-TR criteria for Cannabis Dependence, Without Physiological Dependence (see Table 4). He presented with a maladaptive pattern of recurrent marijuana use despite its negative impact on his mood and school attendance. Additionally, despite his persistent desire to better control his substance use behaviors, Adam continued to use marijuana for longer periods than he had intended.

\section{Strengths}

Adam presented with many strengths. He sought out therapy of his own volition in order to address his recent decline in functioning. Despite his doubts regarding whether he would be able to feel better emotionally or improve his academic performance, he demonstrated motivation and engagement from the start of therapy. In addition, he was very intelligent, open to feedback, and a hard worker. Adam also evidenced good interpersonal skills and was wellliked by people. He had a strong friendship network from his high school and a very close relationship with his sister, whom he spoke to at least weekly on the telephone since he had moved away to college.

\section{CASE FORMULATION AND TREATMENT PLAN}

\section{Formulation}

When Adam was 13 years old, he started to recognize that he was aroused by fantasies about men. Meanwhile, Adam's male classmates were "obsessed” with "hooking up with girls;" heterosexual relationships were highly visible and considered the norm. As Adam’s own sexual 
identity awareness started to emerge, he was exposed to his classmates' ridicule of sexual minorities, his church's view of nonheterosexuality as an "abomination," and his own parents' negative views toward gay people. As a result, he internalized the cultural stigma he was surrounded by and developed the schema that he was "abnormal” and "defective” because he desired men.

Throughout his teenage years, Adam's schema of defectiveness was continuously strengthened by the rejection of sexual minorities by both his family and society. His schema gave rise to depressive symptoms, including the belief that his sexual identity was an insurmountable problem that would result in him being “alone forever." Adam originally coped with his depressive thoughts and feelings via relatively healthy distraction techniques, such as spending time with friends and immersing himself in schoolwork. Yet once he began college and was faced with his decision to come out at that time, his depression began to mount as he imagined people's reactions to his disclosure. His fortunetelling maladaptive thoughts such as, "I won't be accepted," served to strengthen his defectiveness schema.

In order to cope with his mounting depressive symptoms, Adam engaged in withdrawal and avoidance behaviors. In his depressive state he limited contact with the outside world and, as a result, received meager positive reinforcement from his environment. Also, since beginning college, Adam had attempted to reduce his symptoms by smoking marijuana, which was negatively reinforcing since it temporarily reduced his depression. When he started to come down from the high, however, his depression increased. His marijuana smoking also exacerbated his withdrawal and avoidance behaviors because after he smoked, his motivation to attend school classes or complete homework assignments decreased. In addition, it appeared that the physiological effects of his depression, including insomnia and difficulty concentrating, were interfering with Adam's ability to complete classwork. Ultimately, his academic decline only served to reinforce Adam's symptoms of depression because he viewed himself as a "failure" for not receiving A’s.

\section{Treatment Plan and List of Treatment Goals}

Applying client-centered, affirmative, and cognitive-behavioral therapy to the particulars of Adam's case allowed for an idiographic treatment approach. Adam's treatment plan was structured to follow a five-phase format, although it was expected that there would be periods in which these phases would not always be linear, and goals from different phases would be worked on simultaneously.

\section{Phase 1: Building Rapport}

Treatment Goal 1: Provide rationale for treatment, establish rapport, and create a safe/validating therapeutic environment. Given that this was Adam's first experience in treatment, I planned to focus the initial stage of treatment on educating him about the therapy process. Ilardi and Craighead (1994) assert that presentation of treatment rationale can profoundly affect positive expectancies regarding the benefits of therapy. In order to increase Adam's hopefulness for improvement, I intended to convey that cognitive-behavioral therapy is 
empirically supported. I would orient him to my treatment style and the process of cognitivebehavioral therapy, including the assignment of weekly homework.

Additionally, I intended to emphasize that Adam could speak openly about anything with me, without fear of judgment. By giving him permission to talk about his sexuality and any other areas that he considered taboo (e.g., his negative thoughts and feelings) I hoped to help create a safe, validating environment in which we could develop a strong therapeutic alliance. Since Adam's discomfort with revealing his emotional state was tied to his family's belief that one should always present a "happy face," it would be important for me to convey to Adam that he need not don his "happy face" with me, and that I could handle his emotional distress.

\section{Phase 2: Targeting Depression.}

Treatment Goal 2: To decrease Adam’s depressive symptoms to a BDI-II score in the absent to minimal range. Cognitive-behavioral therapy for depression emphasizes behavioral techniques, especially for clients who are passive and anhedonic (Young, Rygh, Weinberger, \& Beck, 2008). In Adam's case these techniques would be especially warranted because he was caught in a vicious cycle in which his reduced activity level resulted in him labeling himself negatively ("I'm a failure for missing class"), which led to even further discouragement. I planned to integrate behavioral activation into Adam's treatment in order to introduce greater feelings of mastery and pleasure in his daily living. These interventions would hopefully increase positive reinforcement in Adam's environment and combat his avoidance behaviors.

Once a depressed client demonstrates significant behavioral improvement, the emphasis of cognitive-behavioral therapy shifts toward the content of the client's cognitions (Young et al., 2008). At this stage of treatment, I planned for Adam to monitor his thoughts in order to learn how to recognize and identify specific, problematic beliefs. Challenging Adam's automatic thoughts by enabling him to generate alternative interpretations would be a skill Adam could hone in session and between sessions, as homework. I hoped that these cognitive restructuring skills would provide Adam with an adaptive coping strategy that he could then utilize independently for the rest of his life.

\section{Phase 3: Addressing Substance Use}

Treatment Goal 3: To decrease Adam's marijuana use. In order to increase Adam's motivation to alter his marijuana intake, I planned to incorporate harm reduction, motivational interviewing, and cognitive-behavioral treatment techniques. Harm reduction seeks to individualize treatment to reduce drug-related harm to clients, without necessarily eliminating drug use (Denning \& Little, 2012). Central to the harm reduction approach are motivational interviewing techniques, which focus on client-centered care and the use of empathy, open-ended questions, and reflections in hopes of increasing clients' ambivalence about their drug use and thereby increasing motivation to change their behavior (Miller \& Rollnick, 2002). I planned to "roll" with any resistance Adam presented in regard to his substance use and support his selfefficacy to change his behavior if and when he was ready to do so. I also intended to assist Adam in challenging any maladaptive beliefs he held regarding his substance use. 
Treatment Goal 4: To increase Adam's class attendance and completion of class assignments. Although he may meet this goal during the behavioral activation (second) phase of treatment, I hypothesized that Adam's reduction in marijuana use would also likely be instrumental in increasing his class attendance and completion of coursework. Presumably, by this stage of treatment Adam's depressive symptom of difficulty concentrating would have improved and thus he would be able to reengage with his schoolwork more easily.

$\underline{\text { Phase 4: Addressing Gay Identity Issues. }}$

Treatment Goal 5: To increase Adam's awareness of his internalized homophobia. Even though this goal would begin to be addressed from the start of treatment (e.g., simply administering the IHP may increase Adam's awareness of his internalized homophobia), I intended to focus this phase of treatment on educating the client about cultural stigma, and helping him to explore it within himself. Throughout this stage, I planned to emphasize that although LGBs experience discrimination, being gay is not the problem and did not cause the oppression. In order to help Adam unearth his internalized homophobic beliefs, I intended to ask him about his own views of what it means to be gay. Additionally, I hoped to help Adam understand the relationship between his religious beliefs and his sexuality.

Treatment Goal 6: To increase Adam's acceptance of his gay identity and decrease his IHP score to the low range. If Adam had been able to recognize his internalized homophobia by this stage of the treatment, my plan would shift to incorporating identity formation and acceptance strategies. I intended to dispel any myths and stereotypes Adam held about being gay. Additionally, I hoped to reframe being gay as positive while at the same time empathizing with the loss he may feel about the life he would never live as a privileged-status heterosexual. I also hoped to reduce Adam's self-stigma by offering information via bibliotherapy and community resources such as LGBT groups.

Treatment Goal 7: To decrease Adam's distress level to an OQ-45 score in the "less than clinical significance" range. A significant treatment goal was for Adam to score in the subclinical range across all of the OQ-45 scales (e.g., total score and subscale scores). Adam's subclinical scoring on this measure would suggest that in addition to no longer feeling depressed, he would also no longer be experiencing distress within his school and interpersonal domains. Presumably, if the previous six goals had been met, his OQ-45 score would reflect a higher level of emotional, social, and academic functioning.

\section{Phase 5: Consolidating Gains and Termination}

Treatment Goal 8: To facilitate Adam's reflection on therapeutic gains and provide relapse prevention skills. In this final phase of treatment, I planned to offer Adam the opportunity to recognize and celebrate his therapeutic gains. Additionally, I intended to strengthen Adam's relapse prevention skills with regard to his depression and substance abuse in order to increase his ability and sense of self-efficacy to care for his mental health needs.

Treatment Goal 9: To provide Adam with the space to process treatment termination. I planned to focus the final stage of treatment on encouraging Adam to reflect upon our 
therapeutic relationship and our upcoming treatment termination. I intended to elicit from Adam what it had been like to work with me in his therapy.

\section{COURSE OF TREATMENT}

\section{Phase 1: Building Rapport}

Sessions 1-3: Developing Rapport, Creating a Safe/Validating Therapeutic Environment, Introduction to Therapy, and Gathering Additional Data

As would be the case with any client, my initial goal in Adam's treatment was to facilitate a therapeutic relationship within a safe and validating environment. Safety and validation were especially warranted in Adam's case since, as a sexual minority, he had spent many of his years being exposed to messages from society and his loved ones that his sexual orientation was problematic and abnormal.

When Adam disclosed his sexual orientation to me in session \#1, his nonverbal behaviors (e.g., averting eye contact, slouching into himself) suggested significant discomfort and anxiety. I knew that how I reacted to his disclosure would be important, and needed to convey my total acceptance of him. I thanked Adam for revealing his sexual orientation to me, and leaned forward toward him in my chair while making steady eye contact as I shared with him that I was "so glad" that he was able to tell me that he was gay. I validated his sexual orientation, stating that such feelings toward the same sex are both appropriate and natural. By providing an affirmative and genuine response to his disclosure, I hoped that my modeling of an accepting stance toward his sexual orientation would instill Adam with the notion that others may accept him, too. I asked Adam how it was for him to disclose his orientation to me, and he replied that he was "uncomfortable" telling me, but that my reaction was a "relief." He added that he wanted to "do therapy right" and believed that he needed to be honest about who he was in order to benefit from treatment. I normalized his discomfort, stating that it made sense for him to feel anxiety about my reaction to a part of him that he had kept secret for a long time.

Adam's disclosure provided me with an important clinical lesson: to not assume heterosexuality, even when clients may indicate a heterosexual orientation during a phone intake or on intake forms. I had assumed that Adam was heterosexual based upon the phone intake I was provided with, not fully understanding that phone intakes and intake forms are relatively impersonal means of gathering information from patients. Additionally, Adam may have felt more comfortable telling me about his sexual orientation after I explained that our work together was confidential, which is often even more paramount to LGB clients (Sue \& Sue, 2013). For clients who are at the initial stages of identity development (which was the case with Adam), such disclosures may occur in the treatment after the therapist is considered a safe confidant.

In this first phase of treatment, I also gathered additional information about Adam, including his symptomatology, family history, and academic functioning. With regard to his depressive symptomatology, it became evident that Adam was experiencing a Major Depressive Episode. I provided Adam with psychoeducation regarding his depressive symptoms, including 
his difficulty concentrating and insomnia, in order to instill the concept that his recent academic problems were not necessarily the result of what he was labeling as "laziness." During session \#1, I started to piece together my case formulation for Adam, including the origin of his depressive episode. Initially, I hypothesized that his depression had emerged due to a difficulty with transitioning to college and moving to a large, urban city. However, after I gathered additional information about Adam's history, and, in particular, his sexual identity development, it became clear that the origin of his depression could be directly tied to significant internalized homophobic beliefs, or schemas, about himself.

In session \#2, I asked Adam if it would be okay for me to ask him more about his sexuality. By asking for his permission, I hoped to convey two messages: (i) that he had control over the pace of therapy, (ii) it was safe for him to speak about his sexuality with me, and that this information could potentially be helpful in the treatment. Adam agreed and provided me with greater detail about his identity development, history of sexual attractions, emotional intimacy, and sexual behaviors. Although Adam had girlfriends in high school and had been sexually intimate with them, his sexual responses were significantly more powerful with his male partner at summer camp. Additionally, in order to reach orgasm during masturbation, Adam fantasized about men. Despite his preference for men, he had "tried" to fantasize about women, in hopes that he could become more aroused by the opposite sex and not in fact be gay.

As he spoke about his sexual history, Adam presented as hesitant and somewhat guarded. Noticing his discomfort, I asked Adam how it was for him to talk about his sexuality. He explained that he grew up in a family in which sexuality was not discussed, and being "proper" was of the utmost importance. I normalized Adam's hesitation to discuss sexuality, stating that it was a difficult subject for many people. By checking in with Adam, I hoped to gauge whether the topic of sexuality was overwhelming to him. Adam stated that, despite it feeling "weird" to discuss sexual topics, he felt comfortable doing so with me because he did not feel that I was “judging” him.

I continued to assess for Adam's comfort level in order to maintain empathic attunement, increase his self-awareness in regard to his emotional state, and support his ability to verbalize his internal experiences. Since Adam's family had instilled in him the notion that emotions should be kept to oneself, my continuous checking in behaviors served to challenge his previously held standard that difficult thoughts and feelings should remain private. I also hoped that my checking in with him would convey my care for him, in that I was attuned to his emotions and accepted whatever experience came up for him.

In session \#3, I provided Adam with feedback from the assessment and we compiled a problem list, which would serve as a guide throughout treatment. Adam and I agreed that we would work to (i) reduce his depressive symptoms, (ii) increase his class attendance and homework completion, (iii) reduce his marijuana use, and (iv) make space in the therapy to explore his sexual identity. Although I recommended that he consult with a psychiatrist in order to determine whether antidepressant medication could augment our therapy, Adam was adamant that he did not want to take psychopharmacological drugs. He agreed, however, to consider taking medication if his depressive symptoms did not start to abate within the first two months of treatment. 
In order to orient Adam to therapy, I described my supportive, active, and collaborative treatment style. I explained that there is a close relationship between thoughts and emotions, and that we would target Adam's depression using a cognitive-behavioral therapy format in which he would be working toward changing his maladaptive thoughts and behaviors. I also informed him that I would be asking him to fill out several measures every other week and that homework would be assigned on a weekly basis. As I was completing a one-year practicum placement as part of my doctoral training, I explained to Adam that we would have up to approximately ten months to work together. Adam said that he was motivated to attend treatment and work to address his problems "head-on."

\section{Phase 2: Targeting Depression}

\section{Sessions 4 - 8: Targeting Depression Via Behavioral Activation Techniques}

In session \#4, Adam shared that he had felt more hopeful about the future directly following our previous session, but soon afterward he began to ruminate that he was going to fail out of college, and his mood declined. Adam said that he had tried to complete his classwork, but found himself reading the same sentences multiple times because he could not digest the information in front of him. He also shared that he had spent much of his week in bed, and was not returning phone calls to his friends from high school.

In order to reduce Adam's avoidance behaviors, I oriented him to behavioral activation. I discussed the link between thoughts, behavior, and mood by drawing the "CBT triangle" and introduced the concept of activity monitoring. Between sessions \#4 and \#5, Adam was assigned homework to systematically observe his behavior with the Weekly Activity Schedule in order to (i) gather data regarding his daily life activities and (ii) plan activities that would provide him with both mastery and pleasure. Adam agreed to complete the assignment and appeared motivated to do so.

The next week, Adam cancelled our session last minute because he said he was feeling ill. Then the following week, he cancelled our session the evening beforehand, citing an exam the following day that he needed to study for. Adam showed for the next session (\#5), and when I asked him if he had completed the activity monitoring for the prior weeks, Adam sheepishly replied that he had not. He then admitted that he had cancelled our previous two sessions because he had not completed the homework assignment, and was ashamed that he was not putting an "adequate effort" into treatment. He worried that I would be disappointed in him, and figured that if he had another week, he would be able to attend the following session with the completed homework assignment. It appeared that Adam's depression-induced avoidance behaviors, in interaction with his high need for approval, were interfering with the first stage of treatment.

In order to reduce Adam's shame and embarrassment, I normalized his difficulty with completing the homework assignment, especially given his depressed mood and lethargy. I also shared that I did not think less of him for not completing the homework, and that his difficulty completing the assignment meant that perhaps I had asked too much from him, which was my mistake. I emphasized that what was most important was for him to show up to treatment, 
regardless of whether he completed assignments, and that we could work through any difficulties he may have encountered, as a team. Adam appeared more relaxed after this dialogue, and said that he would make sure to come to treatment even if he did not complete assignments in the future. In order to relieve some of the pressure Adam was feeling about the homework and hopefully reengage him in treatment during these essential first sessions, I told Adam that his only homework for the following session was to attend therapy the next week.

Adam attended the next session (\#6), where, together, we reconstructed his previous week using the Weekly Activity Schedule form. Much of Adam's week had been spent in bed, watching television, and in general isolation. I explained that his tendency to stay in his dorm room and withdraw from the world around him only perpetuated his symptoms of depression, and that it was necessary for him to learn how to actively engage with his world (by going to classes, socializing, etc.) even if he felt depressed. These interventions sought to increase positive reinforcement in Adam's environment and combat his avoidance behaviors.

Adam and I scheduled pleasurable activities for him to engage in on a daily basis, which included calling friends from his high school, speaking to his sister, going for a light jog, and playing his guitar. For every task, I asked Adam to imagine each step that would be involved in accomplishing the activity. For example, before he went for a jog, he would need to locate workout clothes. Where was this outfit? Did he have sneakers? Would he want to bring music with him during the workout? Since Adam had been struggling with low energy, difficulty concentrating, and self-defeating maladaptive thoughts, "grading the tasks" into smaller chunks (Young et al., 2008) helped to make them more manageable and highlighted any potential setbacks that could have emerged. For example, one of the strings on Adam's guitar had snapped, and he did not have a replacement. In order to accomplish playing the guitar, he needed to schedule a time to visit a nearby music store to buy new guitar strings. Planning out these activities in such detail made it more likely that Adam would feel capable of achieving them.

Adam arrived at session \#7 with a notable decrease in his depression. He had attended all but one of his classes, which he explained he was able to do by reminding himself that he needed to act as if he were not depressed in order to ultimately feel better. He shared that although he did not complete all of the tasks we had scheduled for the previous week, he had completed most of them, and derived pleasure from quite a few of the activities. Noticing a reduction in his allor-nothing, perfectionistic thinking, I praised Adam for commending himself for the significant effort he had exerted over the previous week.

Earlier in treatment, Adam tended to focus exclusively on what he had not accomplished as opposed to what he had accomplished; there appeared at this point to be a shift in how Adam was thinking about himself, as he was beginning to acknowledge his own accomplishments. Indeed, engaging in scheduled activities seemed to improve his mood because he derived positive rewards from his environment on a more consistent basis. His ratings of mastery and pleasure also contradicted his erroneous beliefs that he could not derive feelings of satisfaction and accomplishment. Additionally, being active rather than passive provided Adam with a sense of agency. Adam noted, however, that although he had spoken to a few friends from home, he wanted to establish friendships at college, too. I suggested that Adam begin to increase his social 
network on campus by joining student groups, such as the meditation group he had voiced interest in. We looked up the meeting time for the meditation group on my computer in order to schedule it into Adam's next week, noting the location of where the meeting would take place.

Adam came to session \#8 with a completed Weekly Activity Schedule, which indicated that he had attended all but two of his classes the prior week, had gone for a run on most of the days, played the guitar, and had attended the meditation group. Adam was also finding it easier to complete his schoolwork as his concentration was starting to increase. He was continuing to smoke marijuana by himself, but only after he had completed his homework. Adam shared that he also smoked marijuana with his dorm-mates several times over the course of the week, and he liked having time to socialize with them. I praised Adam for having completed the prior week of activity monitoring, which provided us with an enormous amount of data to draw from. He noted that his depression seemed to be lifting, as he was able to enjoy himself throughout the previous week. Adam also noticed a pattern that he was typically happier when he was engaged in an activity that distracted him from his thinking.

During session \#8, Adam appeared less lethargic and spoke with a brighter, more confident voice. Yet he noted that despite feeling better, he was lonely and still felt like a "failure" for receiving B's and one C on his midterms. Adam believed that he had "screwed [himself] over" by isolating himself at the start of college, because he "missed [his] chance" to make friends. By now, Adam said, people had already established their friendship circles, and therefore it was "too late" for him to make friends of his own. I introduced Adam to the concept of cognitive restructuring, and explained that in addition to increasing positive activities throughout his daily routine, now we would also be exploring the content of his automatic thoughts. As homework, Adam was assigned to complete another Weekly Activity Schedule and look up the time and location of the college's artist group, which he had voiced interest in. He also was assigned to ask at least one person from either the meditation group or artist group to get a coffee with him.

\section{Sessions 9 - 16: Targeting Depression Via Cognitive Restructuring}

Once a client demonstrates significant behavioral improvement, as was the case with Adam at this stage in the treatment, the emphasis of cognitive-behavioral therapy for depression shifts toward the content of the client's cognitions (Young et al., 2008). Starting in session \#9, Adam began to monitor his thoughts in order to learn how to recognize and identify specific, problematic beliefs. For example, Adam said that the previous week he started to feel depressed while he was studying one evening. I sought to uncover Adam's automatic thoughts by asking him, “what was going through your mind right before you started to feel depressed?” Adam said that he had been thinking about his current grade for that class (a " $C$ "), and felt like a "failure" for letting the course "slip away" from him. He had always been a straight A student, and was scared of what his parents would say about his grades. Adam shared that he believed that he had "thrown away" his college education, which he had worked so hard to attain, and was angry for having gotten himself into this situation.

Adam and I challenged the accuracy of his automatic thought by marshaling evidence that both supported and refuted the belief that he was a "failure" for receiving a "C" midterm 
grade. Together, we filled out a Dysfunctional Thought Record, which posed the following questions: "What is the evidence that the automatic thought is true? Not true?;" "Is there an alternative explanation?;" "What's the worst that could happen? Could I live through it? What's the best that could happen? What's the most realistic outcome?;" "What's the effect of my believing the automatic thought? What could be the effect of changing my thinking?;" "What should I do about it?;” "If ___ [friend's name] was in the situation and had this thought, what would I tell him/her?” (Beck, 1995, p. 126).

At first, Adam was highly critical of his ability to complete the Dysfunctional Thought Record, and said, “I can’t even do this correctly. I am a failure.” I normalized Adam's difficulty with the exercise, stating that as with any new skill, it takes some time to master. I also told him that I would help him complete it. After filling out his thought record, Adam was able to recognize that he was enrolled in a top university with an excellent academic reputation, and that he would not have gained entry into the college if he were a failure. Additionally, he noted that he was engaging in several of the thought distortions from the cognitive distortions list. For example, he recognized that the fact that he received one " $C$ " grade was not representative of his general intellectual capacity, and therefore his initial thought that he was a failure was an example of polarized, all-or-nothing thinking. Adam also said that he was engaging in magnification because he generalized his total self-worth based upon this one midterm grade. Additionally, he noted that he was catastrophizing by believing that he would flunk out of university, since there was little evidence to support that belief. In fact, Adam acknowledged that perhaps he could work to improve upon his $\mathrm{C}$ grade by attending his professor's office hours and catching up on readings he had missed earlier in the semester. By the end of this exercise, Adam's belief in the thought that he was a failure decreased in strength from $99 \%$ to $45 \%$, and he reported decreased feelings of depression and anger.

Challenging Adam's automatic thoughts by enabling him to generate alternative interpretations was a skill that Adam also honed outside of therapy sessions by completing thought records for homework. I asked Adam to notice when he had a negative automatic thought, and to write it down with its corresponding cognitive distortion label (e.g., "catastrophizing” that he would fail out of college). I also tailored homework assignments specifically to Adam. For example, he was especially affected by the last question on the Dysfunctional Thought Record form: "If [friend's name] was in the situation and had this thought, what would I tell him/her?” When completing the previous Dysfunctional Thought Record, Adam imagined his sister calling herself a failure for receiving a C. Adam found this to be a powerful exercise because he could not envision his sister as a failure for receiving a $C$ grade. For homework, I asked Adam to write, "If my sister were in the same situation and had this thought, what would I tell her?” onto a notecard and place it in his wallet for easy access. When he recognized his mood shifting in a negative direction, he would identify the automatic thought and ask himself what he would tell his sister if she had the same thought.

By completing the Dysfunctional Thought Record in session and between sessions, I sought to assist Adam in drawing rational conclusions that would guide cognitive, behavioral, and emotional change. Acquiring restructuring skills provided Adam with a healthy coping strategy that he could ultimately utilize independently, which would empower him to care for his own mental health needs. 
In sessions \#10 - 14, Adam continued to increase his activity level and honed his cognitive restructuring skills by uncovering and refuting additional depressive automatic thoughts in session and between sessions. It became clear that Adam was continuing to struggle with a significant fear of lack of success and concern that he would not live up to his family's expectations. This was especially apparent while he was taking his final exams at college. Adam was worried about returning home to his family for a week during the Christmas holiday; he knew that his parents would ask about his academics, and feared that his grades would disappoint them. But as Adam's depressive symptoms had decreased, he threw himself back into his schoolwork, and was able to attain excellent grades on his finals.

In session \#15, Adam revealed that he believed, “If I'm not working, then I'm a lazy person.” He explained that the pressure his father placed on him to be a straight-A student had led to Adam's strong work ethic, and that he felt pride in accomplishing academic achievements. In my work with Adam, I sought to soften his perfectionistic strivings by noting what he was giving up for his "perfect” school performance: the social life that he so longed for. After completing a Dysfunctional Thought Record to challenge his belief, "If I'm not working, then I'm a lazy person," Adam altered his belief to "I can work hard and still make time for other important things, such as making and seeing friends."

After completing this thought record, Adam uncovered an additional thought: on some level, he believed that if he worked hard enough and was successful, his father would accept him, even if he were gay. Adam began to cry after he shared this thought, and said that he started to become "obsessed" with being the "perfect child" when he was 13 years old, when he began to recognize his same-sex attractions. In a desperate attempt to be loved and accepted by his father, Adam tried to be the perfect student and son. This was the first time that Adam had ever cried in my presence. Since he had not been permitted to express his emotions, let alone sob, in front of his family members, I knew that his crying in session presented a very important therapeutic moment.

As I hoped to provide Adam with a new experience regarding emotional expression, I sat quietly with him as he cried, offering him the space to safely release his feelings without judgment or negative consequences. Adam asked me if I thought he was a "mess" because he was crying, and added that he "should be stronger." I told him that I was glad that he asked me how I viewed him in this moment, and shared with him that I felt enormous care for him, and was incredibly proud of him for being able to access thoughts and feelings that he had kept buried deep within him for so long. I reminded him that emotions such as sadness are a part of everyone's life, and that allowing them to be expressed in a healthy way, like crying, was a sign of emotional strength.

It was not lost on me that up to this point in treatment, Adam rarely ever spoke about his sexual identity with me. At the start of therapy, it was clear that he held the core belief that he was "defective" because he was gay, and he was struggling with maladaptive automatic thoughts related to his sexual orientation. Yet each week he came to session with examples of automatic thoughts that were usually related to his school performance. I purposely did not want to push Adam to speak about his sexuality before he was ready to do so, and since he evidenced mood improvement, my supervisor and I decided to continue to let him take the lead with whether to 
bring his sexuality into the forefront of treatment. Yet ultimately, it became clear that much of the work we had been doing together was directly related to his discomfort with his sexuality. Driving much of Adam's struggle with academic endeavors was actually his core belief that he was "abnormal” because he was gay; since he viewed himself as "defective," he needed to prove his worth via other means, such as being a "perfect," straight-A student.

By session \#16, Adam had already mastered his cognitive restructuring skills, and his depression had lifted considerably. Adam was starting to recognize, however, that his continual marijuana use was negatively impacting his mood as he came down from the high, and that this was a problem that needed to be addressed. Yet Adam shared that the only time he felt "normal" was when he smoked marijuana; when he was high, he allowed himself to fantasize about men, and his anxiety about his sexuality significantly decreased. It appeared that Adam was now giving me permission to address his marijuana use and sexual identity in therapy, which initiated the third phase of treatment.

\section{Phase 3: Addressing Substance Use}

Sessions 17 - 21: Addressing Substance Use Via Cognitive-Behavioral, Harm Reduction, Motivational Interviewing, and Mindfulness Techniques

Despite its negative impact on his mood and academic performance, Adam was ambivalent about reducing his marijuana use. When Adam smoked marijuana, he allowed himself to fantasize about men and did not experience the influx of negative automatic thoughts about his sexuality that he would while sober. Additionally, smoking marijuana provided him with a form of relaxation, a break from his perfectionistic strivings, and the opportunity to socialize with his dorm-mates.

In session \#17, I elicited from Adam the pros and cons of his substance use in order to increase his ambivalence about using marijuana and bring him closer to "change talk," in which he would begin to verbalize his interest in altering his substance use behavior. Expressing empathy, I reflected back to Adam that it made sense to me that he was reluctant to disown a drug that had served many positive purposes in his daily living. Adam shared that his use also had negative consequences: he was continuing to skip approximately one morning class per week, which he believed was directly related to his smoking marijuana the night before. In addition, after missing the class, he would castigate himself for his "slacker" behavior, and thereafter feel depressed.

Adam acknowledged the drawbacks of using marijuana and said that "something ha[d] to change.” Adam asked me directly if I believed that he should stop using marijuana outright. In order to support his autonomy, I responded, "It seems to me that you have a number of choices that you could make with regard to your substance use." I then segued to an introduction of harm reduction therapy. I explained that in harm reduction, the goal is to reduce the negative consequences of using a substance in an individualized, tailored manner, which may mean changing how one uses the substance, the frequency of use, or stopping it entirely (Denning \& Little, 2012). I wondered aloud if Adam was interested in changing his substance use behavior in order to attend all of his weekly classes. 
Adam said that he was motivated to change his marijuana use because his academic functioning was too important to him to compromise anymore. But Adam added that perhaps he could continue to use marijuana, albeit in a healthier way. He wondered if he could start to smoke only on the weekends, as he did in high school. Smoking on the weekends, he said, never interfered with his schoolwork. I reflected Adam's statements back to him, and stated that smoking daily appeared to be affecting his ability to get to class right now. I added, "Now you're thinking about changing your use so that it will be less likely to affect your academics. That sounds great! Would you like to think about how you can go about changing your behavior?" Adam responded, "I think that would be a good idea." At this point in the treatment, my role was to build Adam's motivation for change while supporting his confidence to do so. I also needed to offer Adam direct guidance in regard to navigating sober time during the school week.

Together, Adam and I identified high-risk situations that could potentially lead to his smoking marijuana. Adam shared that it would be very hard for him to imagine spending time with his dorm-mates if he did not smoke marijuana with them. He had never socialized with them while sober, and they were all "pot heads." Additionally, Adam imagined that it would be difficult for him to resist spending time with them, especially if they were to seek him out by knocking on his door at the end of the day.

Initiating a role-play exercise, I asked Adam to act out how he would tell his dorm-mates that he could not join them that night. Adam decided that he could tell them that he had too much schoolwork. At that moment in our session, Adam's affect changed; when I checked in with him to find out what he was thinking and feeling, he told me that he would feel lonely and as if he were missing out on a "fun time" if he did not use with them. I asked Adam how he would feel about rewarding himself with smoking marijuana with his dorm-mates on the weekend, when it would be less likely to affect his school attendance. Adam said that he could try out this plan.

Adam and I also brainstormed activities for him to engage in at the end of the day that could serve as rewarding replacement behaviors. Since he began college, he looked forward to using after completing a day of classes and studying, and found the marijuana high to be relaxing. Since Adam believed that turning down the opportunity to socialize, in particular, would be difficult for him, he suggested that he speak to friends from his high school on the phone in order to feel connected with others in a healthy way. He also believed that playing his guitar would be both relaxing and satisfying. I praised Adam for his great suggestions, and said that we would try out this new plan as an experiment, and review how it went in our next therapy session. I also asked him to write down the pros and cons of his marijuana use on a notecard, and to read it each morning and evening.

In session \#18, I asked Adam how our harm reduction plan was working. Adam reported that he had abstained from using marijuana on all but one weeknight, but had missed his morning class the day after he used. In order to gather information about what had happened the night that he used, I asked Adam to describe the evening for me in detail. Adam shared that on the weeknight he used, his dorm-mates had come looking for him to smoke with them. Just as he had role-played in session, Adam told them that he was too busy with work to spend time with 
them that night. He then attempted to contact his friends from high school over the phone, but was unable to reach them. His sister was also busy. Adam started to feel lonely, and decided that socializing was also important to his mental health. He sought out his dorm-mates with the plan to abstain from using and spend only 20 minutes with them for some "down-time;" but when they passed a joint to him, he smoked. Adam recognized that being in the presence of marijuana made it very difficult for him to stay sober - yet he desperately wanted to be socializing with his peers.

I framed Adam's use of marijuana not as a failure, but as an opportunity for learning that we could build upon in treatment. From this experience, Adam had learned that (i) being around marijuana was a formidable trigger for using and (ii) he was lacking a social circle of non-users. In the first instance, it was clear that avoiding being in the presence of marijuana during the weeknights would reduce the likelihood of his using. Second, Adam had started to frequent the campus' meditation and artist groups, and perhaps he could increase his social network by continuing to reach out to his peers in those settings. Adam agreed to attend the groups over the upcoming week, and to ask members of the group to make weeknight evening plans with him.

In session \#19, Adam shared that he had abstained from using marijuana on each of the weeknights and had attended all of his school classes. However, he had struggled with strong urges to use each evening, which he found to be frustrating. He wondered aloud in session if he would always need to contend with these cravings. Although distraction techniques (e.g., seeing two new friends from his meditation group) appeared to be helpful, Adam continued to think about smoking. Each time the thought of marijuana came to mind, he thought to himself, "Not smoking is too hard for me” and "I don't think I'll be able to pull this [harm reduction] plan off."

It was clear that I needed to educate Adam about the nature of cravings and urges. I explained that urges to use are a normal, expected response to changing substance use behaviors, and did not indicate that he was not putting in great effort to alter his use. I told Adam that he should expect to experience strong urges to use marijuana, and that he could practice helpful coping tools when they arise. For example, he could practice "surfing with the urge," in which he could observe his craving, examine it with curiosity, and watch it as if it were a wave building up on the beach (McCrady, 2008, p. 517). Just like a wave, the urge would build, reach its peak, and then dissipate. Adam could ride this urge as if it were a wave, knowing that it is a time limited experience that will ultimately pass.

As Adam had been voicing interest in meditation (e.g., he was attending the university's meditation group), I decided to focus the rest of session \#19 on mindfulness-based practice. I likened urge surfing to a mindfulness exercise in which one accepts whatever internal experience emerges, without judgment. I introduced Adam to a relatively newer form of behavior therapy, called Acceptance and Commitment Therapy (ACT), which emphasizes the use of mindfulness and acceptance practices. A preliminary study suggests that ACT is useful in the treatment of marijuana dependence (Twohig, Shoenberger, \& Hayes, 2007) because participants were taught that urges and thoughts about using marijuana could be experienced but not acted upon. I explained to Adam that ACT therapy seeks to enhance clients' willingness to experience and accept negative private events and thoughts because suppression only amplifies what one hopes to avoid (Hayes, 2004). 
Adam was eager to learn more about ACT therapy. For homework, I asked that he buy the book Get Out Of Your Mind And Into Your Life in order to learn more about ACT and to practice the mindfulness exercises, which are featured throughout the text (Hayes \& Smith, 2005). I also suggested that Adam practice mindfulness and relaxation exercises in the weeknight evenings, after he completed his schoolwork, as an alternative to using marijuana. In order to increase Adam's relaxation skills, I led him through a diaphragmatic breathing exercise. Adam found the breathing to be helpful, and said that he was interested in my leading him through another relaxation exercise in our next session. I asked him to bring a recording device so that he could tape the relaxation exercise and then listen to it between our sessions.

In session \#20, Adam reported that he had abstained from using on all of the weeknights and had attended all of his classes. He found it easier to navigate his cravings by practicing "urge surfing” and distraction techniques. I introduced Adam to Progressive Muscle Relaxation and led him through an adaptation of the "floating leaves on a moving stream" mindfulness exercise (Hayes \& Smith, 2005, pp. 76-77). He audio recorded my instructions and said that he was looking forward to practicing the relaxation and mindfulness exercises between our therapy sessions.

When Adam showed to session \#21, he said that he had been struggling with a depressed mood since the weekend. He had abstained from using marijuana on all the weeknights and had attended all of his classes, but over the weekend, he smoked throughout Saturday and Sunday, and did not complete necessary homework assignments. Adam said that he had been struggling with feeling "abnormal" because he was not spending time with his dorm-mates during the week; he viewed his inability to smoke marijuana with them during the school week as evidence that he was "weird." Adam shared that before he spent the weekend smoking marijuana, he had been thinking to himself that abstaining from marijuana during the week provided even more evidence that he did not "fit in." After completing a Dysfunctional Thought Record in session, Adam realized that he smoked throughout the weekend with his dorm-mates and by himself in order to "numb" himself from his thought that he was abnormal because he was gay.

I framed Adam's weekend as a "slip," which provided valuable information for us to look at together. First, it was clear that Adam could benefit from additional friends who did not use marijuana; this would afford him the opportunity to challenge his belief that being normal means that one needs to smoke pot. Additionally, I shared with Adam that his discomfort with his sexuality appeared to be propelling his use, and that perhaps we could make greater space in the therapy to uncover his feelings about being gay. Adam agreed that it was time for him to address his feelings about his sexuality, but stated that he was "scared" to do so. When I asked him what he was scared of, he replied that he feared he was "doomed" to live a life alone, with no romantic partner and no family. He would "always" be relegated to outcast status in society. Adam said that it would be too painful to talk about these "facts" in therapy, and make his fate all the more "real." Smoking marijuana, he explained, helped rid himself of these thoughts, and relieved him of his feelings of loss about the life he would never be able to live. I shared with Adam that although he was correct that sexual minorities were victims of stigma in our society, there were many gay people who were able to attain healthy, loving, romantic relationships, and create families of their own. 


\section{Sessions 22 - 25: Addressing Substance Use Via Social Support Network}

In session \#22, Adam shared that he had abstained from using marijuana during the weeknights and had attended all of his classes. However, on Saturday he spent the day smoking marijuana with his dorm-mates. Adam was angry with himself for using all day, and said that come Sunday, he had the realization that he no longer wanted to use marijuana anymore. In the past, he explained, he had been able to limit his use so that it did not interfere with his functioning; but now, he was starting to see recurrent negative consequences to using. Adam said that if he was going to focus on himself, and truly address his sexuality in treatment, he needed to stop using and confront his fears about being gay "head-on."

In order to support his newfound goal of total abstinence from marijuana, I suggested that he focus on increasing his social network to include non-users. Adam said that he was ready to separate from his dorm-mates and challenge himself to make new friends, even though he knew he would miss spending time with his dorm-mates. I told Adam that there were Marijuana Anonymous (MA) groups available to him in the city, which could provide a valuable resource for him as he navigated abstinence. Additionally, I explained that a major benefit of MA groups is that they inherently provide people with a sober social support network. Although Adam typically embraced my therapeutic suggestions, he looked dubious as I spoke about MA. When I checked in with him regarding what he was thinking, he asked me if MA was similar to Alcoholics Anonymous (AA), where there is a strong emphasis on religion. I explained that like AA, MA is based upon the 12-step model, in which there is a spiritual component to the program.

Adam shared that he was hesitant to become part of a group that emphasized religion due to his negative experiences with the Catholic Church. He revealed stories from his childhood and adolescence in which his Sunday school priest described same-sex behavior as a sin and an "abomination." Adam said that he was inundated with the message that his same-sex longings were evidence of his being "sick" and that acting on these impure impulses would be a sin against God. Adam could not imagine willingly attending a group in which he would hear, yet again, how God had "rejected" him.

I empathized with Adam's feelings of anger toward his church, and said that it made sense to me that he did not want to put himself into a situation that could expose him to bigotry. I also shared, however, that unlike his experience with his church, many religious institutions were now gay-friendly. Additionally, I stated that the local LGBT center actually hosted MA and AA meetings. Adam was surprised to hear this, and said that he would look into the MA meetings on the internet as homework and see if he wanted to go to a meeting that week. I wondered aloud if Adam could attend one of the MA meetings as an experiment, with the intention of taking from the meeting what was helpful, while perhaps "tuning out" any religious components that were less appealing to him.

Adam had completely abstained from using marijuana between session \#22 and \#23. He investigated MA on the internet, but did not attend a meeting. Over the weekend, however, he had felt lonely, and realized that he wanted to try to find a network of sober friends, and MA seemed to be the easiest way to locate sober people. Adam said that he would go to a meeting 
before our next session. I asked Adam if he wanted to attend one of the MA meetings at the LGBT center, and he replied that going to the LGBT center would be "too overwhelming right now.” Aware that I had a choice point in the therapy session, I decided that instead of encouraging Adam to attend the MA meeting at the LGBT center, I should focus on increasing his sober social support. I hoped that once he had a more stable friendship base, perhaps he would feel more able and willing to attend the LGBT center's meeting.

In session \#24, Adam shared that he had attended an MA meeting as part of his homework. He decided to speak about his use during the meeting, despite feeling scared to do so, and afterward multiple group members approached and commended him for reaching out for support. Several group members invited him to their weekly dinner at a local restaurant, which Adam joined. Adam was excited about his burgeoning friendships, and had already spoken to two of his new friends on the telephone. He was eager to attend the group again over the coming week. I asked Adam if there had been a religious component to the meeting, and if so, how that was for him. Adam replied that people had referred to a "higher power," but that he "zoned out the religious portion" of what people said; instead he focused on the values that the group members shared.

By session \#25, Adam had continued his abstinence from marijuana, was attending all of his classes, and was receiving strong grades at school. He also shared that he was thinking more about attending the MA meeting at the local LGBT center. At a recent meeting, an openly gay young man spoke about his sexuality and substance use in front of everyone. The group members showed this man support and care, and did not demonstrate any homophobic response to his sexual orientation disclosure. Adam was “floored” by this man's openness and the group members' positive reactions, and said that he was starting to realize that he could imagine coming out eventually, too. When I asked Adam if we could continue to discuss this powerful experience in our next session, he agreed and appeared eager to do so.

\section{Phase 4: Addressing Gay Identity Issues}

\section{$\underline{\text { Sessions } 26 \text { - 28: Uncovering Internalized Homophobia }}$}

By this time in the therapy, Adam's depression had significantly decreased (as indicated via his BDI-II score), he was attending all of his college classes, and he was abstaining from using marijuana. As Adam was beginning to make space in the therapy to discuss his sexual orientation, and was even beginning to consider the possibility of coming out, it was clearly an opportune time to shift the focus of therapy to his sexual identity.

Throughout much of the treatment up to this point, Adam had been fairly transparent with me about feeling "overwhelmed" by his sexual orientation, and actively resisted interventions to increase his awareness and comfort with his sexuality (e.g., refusing to attend the MA LGBT meeting). I struggled with Adam's avoidance of his sexual identity, and often brought up the topic in my supervision for fear that I was colluding with Adam's desire to evade a topic that was paramount to his mental health. Attempting to push away his sexual fantasies, romantic longings, and the gay community served to reduce his anxiety in the short-term. Ultimately, however, avoidance of his sexuality only increased his internalized homophobia and distress 
level. Yet I came to realize that Adam needed a sense of control over the pace of treatment, and that he was in fact allowing himself moments to reflect on his sexuality (e.g., realizing that his need to be a "perfect son” was propelled by his wish to “compensate” for being gay). I conceptualized these moments as Adam tackling the lowest rungs on a sexual orientation exposure fear hierarchy, and hoped that in time, he would be able to further decrease his avoidance of a part of him that for his entire life, he had kept hidden.

At this pivotal point in the treatment, Adam was ready for the next phase of his selfimposed sexual orientation exposure hierarchy, and gave me permission to prioritize his sexuality in the therapy. In retrospect, I believe that my encouragement of Adam to discuss his sexuality when he was able to do so and my steady, affirmative stance toward his sexual identity provided a sense of safety and reassurance that ultimately helped build his confidence to confront his feelings about being gay. My approval of his sexuality may have helped to decrease his shame and guilt regarding his thoughts, feelings, and behaviors related to his sexual orientation.

In session \#26, Adam continued to speak about his astonishment at hearing the man at the MA meeting disclose his gay sexual orientation to a room full of strangers. Adam said that for the first time, he was beginning to feel somewhat more hopeful about his sexuality, as he saw first-hand that a gay man can be accepted by others. Adam said that he was starting to think about telling his sister that he was gay; it pained him that they were "best friends," yet he was keeping such a big part of himself secret from her. I empathized with Adam's wish to tell someone he loved so deeply about his sexuality, but also added that coming out is a process that should be carefully navigated. I suggested that perhaps it would be prudent to spend additional sessions addressing his own feelings about his sexuality before he began sharing it with important people in his life. I said that it could be helpful to uncover his own views about being gay before he elicited those of others.

In session \#27, I led Adam through an exercise that sought to increase his awareness of his negative beliefs regarding sexual minorities. As adapted from Igartua (2012), I asked him to free associate, without editing himself, to the word "gay." Adam listed the following words and phrases: “queer,” “abomination,” “isolation,” “alone forever,” “abnormal,” “AIDS,” “promiscuity,” “sick,” “pervert,” “inferior,” "lonely,” and “persecuted.” Adam added that he grew up hearing his classmates say "that's so gay” whenever they disliked something; therefore, he formed the conclusion that if he were to come out as gay, he, too, would be disliked.

I pointed out to Adam that it made sense that he had drawn a negative conclusion about being gay because he was exposed to homophobia while growing up. I continued that, in his particular case, he had received recurrent messages from his classmates and priest perpetuating the harmful notion that being gay was abnormal. I shared that as a result of societal stigma, it was common for people to internalize negative views of their nonheterosexuality; our work would be to evaluate whether these beliefs he held were accurate. I highlighted that being gay in itself is not the problem, but that external factors such as discrimination are to blame for the negative connotation he was attaching to the word "gay." By evaluating each of Adam's words via Socratic questioning and cognitive restructuring techniques, he was ultimately able to recognize his sweeping generalizations about the gay population, which is in fact quite heterogeneous. I hoped that initiating the breakdown of Adam's stereotypes (e.g., not all gay 
men have AIDS) would serve to reduce his internalized homophobic beliefs and challenge his "defective” and "abnormal” schemas.

At the beginning of session \#28, Adam said that he had continued to think about his free association words throughout the week, and in particular, the words "lonely," "abnormal," and "inferior." He shared that although he did not begin to suspect that he was gay until he began puberty, he had always felt "different" from his peers, even at a very young age. He said that he had expended great effort to conceal this differentness by trying to be "perfect," thereby covering up his perceived inadequacies and shame.

Adam said that since he had stopped using marijuana for the previous six weeks, he had become more aware of his using as an attempt to cope with his shame; now that he was sober, he was allowing himself to reflect more about his sexuality. Whereas previously it had been difficult for Adam to fantasize about men unless he was high, now there were moments when he was able to tolerate his sexual fantasies while sober. Adam sought my advice, asking me what he could do to cope when he reverted to feeling guilt-ridden and ashamed about his sexual attractions. I framed Adam's attractions as a part of him that was both natural and outside of his control. I said that he could practice mindfulness in order to live with his attractions openly and nonjudgmentally as opposed to fighting against them. If he could practice accepting and surrendering himself to these feelings, his shame and anxiety would likely decrease.

Via an intervention adapted from Beckstead and Israel (2010), I asked Adam how he viewed his sexual attractions. Were they a burden? A sin? Natural? A gift? Joyful? I reminded him that how he thinks about his attractions would affect how he feels about his attractions. Adam shared again that he had been "bombarded" with messages from his church that same-sex attractions were "abominations," and he was still having difficulty separating himself from that notion. However, he also stated that he could see the joy in his attractions, as he had experienced intense happiness when he was involved in his first gay romantic and sexual relationship during his summer as a camp counselor.

Adam then shared that he felt lonely because "no one" knew the "real" him; the "only person who ever understood" him was his previous partner at camp, with whom he was no longer in contact. Despite his large friendship circle from high school and his increasingly growing group of friends at college and MA, Adam felt isolated. His first year of college was almost over, and some of his friends from university would be leaving the city for the summer. Adam, however, had secured an internship in the city, and would continue to live in his dorm over the summer months. He was beginning to wonder if he should come out to his friends at college before they left for the summer in order to feel a greater sense of authenticity in his relationships. Adam also wondered if he should speak about his sexuality with someone he was less familiar with. In fact, over the previous week he had considered whether to approach the openly gay man at his MA meeting; but in the end, Adam did not approach him. Adam left the meeting feeling disappointed in himself because he believed that it would have been beneficial for him to reach out to someone who could potentially offer support with regard to his sexual identity and substance use issues. 
I normalized Adam's difficulty with reaching out to this man, and said that it made sense to me that he was conflicted about making contact as he had been motivated by fear for so long to separate himself from all things gay-related. I also praised Adam for his idea to "test the waters" of disclosing his sexual identity to someone who may be able to offer him helpful guidance as he navigates this period of self-discovery. In order to increase Adam's self-efficacy, we role-played approaching this man at the MA meeting. After completing the role-play, Adam said that he felt "more confident," and he assigned himself the task of approaching the man at the next MA meeting for homework.

Sessions 29 - 37: Identity Formation and Acceptance Strategies

As Adam had already begun the process of uncovering and challenging his internalized homophobic beliefs, treatment shifted to identity formation and acceptance strategies. These two strategies sought to further diminish his once formidable internalized homophobic beliefs, and would hopefully arm Adam with useful coping skills. I sought to broaden his perspective regarding his sexual orientation, empower him through psychoeducation and normalization interventions, and increase his sense of self-efficacy to become a member of the gay community, if he so desired.

In session \#29, Adam said that he had gathered the courage to approach Jesse, the man from the MA meeting, and disclosed to him that he was gay. Jesse was very supportive of Adam, and they continued to speak for approximately 30 minutes after the MA meeting had ended. Jesse offered to be Adam's MA sponsor and encouraged him to call if in need of any guidance. They also scheduled a time to meet for coffee to discuss the MA steps over the next week.

Adam said that his interaction with Jesse was a "huge" moment for him because it made him feel "completely understood," accepted, and less "abnormal.” He was excited about Jesse being his sponsor and was looking forward to his upcoming coffee with him later that week. This positive experience led Adam to wonder whether he should attend the MA meeting at the LGBT center, too. He was interested in meeting additional people who identified as gay, but was also scared of "officially outing” himself by attending an event at the center. Adam also shared his discomfort with the idea of being around "flamingly gay" men, whom he found to be distasteful. Jesse, he explained, did not "appear" gay and could easily pass as a straight man. Adam said that he felt more comfortable around a gay man who was not "in your face about it."

As Adam had expressed significantly negative sentiments toward outwardly gay individuals, I wanted him to reflect upon his statements about gay men who did not "appear" straight. I asked him: Where did his feelings of discomfort with outwardly gay men come from? Why was he more comfortable with gay men who appeared straight? I hoped that my line of questioning would help Adam recognize that he was projecting his own self-loathing beliefs about his sexuality onto a substantial proportion of the LGB community. After pondering my questions, Adam said that he associated gay with being less masculine; outwardly gay men made him feel uncomfortable because on some level, he worried that he was "less of a man" because he was gay. 
In response, I provided Adam with psychoeducation about gender scripts, explaining that our culture espouses certain "guidelines" for "appropriate" male and female behavior. I said that these scripts are socially constructed and only serve to devalue the diversity that is inherent across gender presentations. Much like his exposure to societal homophobia, he had also internalized notions about gender, which could be damaging to his sense of self if left unchecked. In this particular situation, Adam's notion of “appropriate masculinity” seemed to be holding him back from reaching out to the gay community. But his experience with Jesse pointed to the fact that contact with other sexual minority individuals could in fact be very helpful for him.

I hoped that by challenging his restricted view of masculinity, Adam would question the prejudicial beliefs he had toward outwardly gay males and begin to accept the multiple, varied presentations of LGB individuals. I also wanted to emphasize that community support from organizations like the LGBT center were a valuable resource for him during this period of identity development. As Adam had felt more "normal” after speaking with Jesse, I hypothesized out loud that his feelings of normalcy could increase as he continued to build contacts with others in the gay community. Adam said that he was viewing gender atypical behavior negatively due to his upbringing, since his father had emphasized the importance of stereotypically male behavior. After I asked Adam if he wanted to create an alternative belief that would challenge his gender script, he shared the following restructured belief: "People who appear outwardly gay may be comfortable with their sexuality, and that doesn't make them less masculine." Adam said that he would continue to think about going to the LGBT center, but was still uncertain about whether he would be ready to go there before our next therapy session.

In session \#30, Adam said that he had met with Jesse over the previous week. Despite feeling accepted and supported by Jesse, meeting with him in public was anxiety producing because Adam wondered if people were assuming that he was gay, and he was still struggling with feeling "abnormal" and "defective" because he was gay. In order to challenge these core beliefs, Adam completed a Dysfunctional Thought Record in session. He identified that his automatic thoughts made him feel angry and sad. He also noted that he had engaged in all-ornothing thinking ("I would only be normal if I were straight"), magnification ("It's awful to be gay"), and mind reading ("The people at this coffee shop can tell that I'm gay"). Adam then disputed his automatic thoughts with the following rational statements: "Being different from the majority does not mean that I'm abnormal or defective," "I'm not responsible for other people's views of gay men,” and "Many people are accepting of gay people.” Adam wrote these statements down on a notecard, which he placed in his wallet. I asked him to read the card daily or whenever he noticed a negative automatic thought emerging about his sexuality.

In session \#31, Adam said that despite feeling less “abnormal," he still felt sad because he would "never" be able to live the "easy life" of a heterosexual. Although Adam's thought reflected the cognitive distortion of magnification, there was also some truth to his statement that I was mindful to not invalidate. I empathized with Adam's feelings of sadness and agreed that he would encounter discrimination based upon his sexual orientation, and that heterosexuals do not have to contend with that stress. I asked Adam to elaborate on his feelings of loss for not being heterosexual, hoping to facilitate a grieving process for the life he would not be able to live as a privileged-status, straight male. 
Adam said that he had always hoped to be married and have children one day, but that reality could "never" happen for him. Via psychoeducation, I informed Adam that many gay men get married (as gay marriage had become legal in specifics states across the United States) or form life-long commitments if marriage is not a legal option in their state of residence. I also shared that gay men can create families with their partners, raising children together. I explained to Adam that raising children and attaining a life-long partnership were both viable options for his future. I recommended that Adam read an article, which explained that gay and straight parents are equally capable of raising healthy children (Barlow, 2013). Adam said that he had never seen a married gay couple before, nor had he met children who had been raised by gay parents. I reminded Adam that just because he had not seen examples of this lifestyle did not mean they did not exist - in fact, if he attended a meeting at the LGBT center, he may learn more about the variety of choices he has in his life direction as a gay man. Adam said that he would feel more comfortable going to the LGBT center with Jesse, and wondered if he should ask him to go to an MA meeting with him there. I praised Adam for his idea, and encouraged him to move through his fear by attending a meeting at the LGBT center in order to attain additional support and knowledge.

In session \#32, Adam said that he went to a MA meeting at the LGBT center with Jesse. Initially, Adam found the center to be "scary" and "overwhelming;" however, after approximately 15 minutes, his anxiety began to decrease. He found the MA meeting to be helpful, as most of the members spoke openly about their LGBT status and some discussed the connection between their drug use and their sexual and/or gender identities. Adam was surprised by how similar he felt to many of the people in the meeting, who seemed to have experienced many of the same feelings Adam had been struggling with. Adam also noted that there were LGB individuals who were confident about their sexuality, and wore it with pride; Adam found this to be inspiring and hoped that one day, he too could feel such pride about his sexuality.

When Adam arrived to session \#33, he shared that he had continued to visit the LGBT center the previous week, and that group members were reaching out to him to spend time together outside of the meetings. Although Adam was excited about these new friendships, he also longed for a romantic relationship. He worried that it would be difficult for him to find a monogamous, committed relationship as a gay man because he believed that "gay men don't commit."

Noting that Adam was engaging in fortunetelling and stereotyping the gay community via the all-or-nothing cognitive distortion, I sought to dispel his homophobic belief via psychoeducation. I shared with him that although gay men may engage in nonmonogamous behavior more than their heterosexual counterparts (or at least report it more candidly in research studies), the nonmonogamous behavior is often negotiated openly within the relationship (Ritter \& Terndrup, 2002). In addition, there are many gay men who strongly adhere to monogamous relationships. I told Adam that being gay did not preclude him from having a stable, monogamous relationship with another man that would be essentially similar to any heterosexual relationship. I suggested that Adam read the book My Guy: A Gay Man's Guide to a Lasting Relationship (Kantor, 2002) in order to learn more about the subject. 
In session \#34, Adam said that he had bought the book, and after reading several chapters, he felt hopeful about attaining the type of relationship he had always longed for. Adam was continuing to attend MA meetings at the LGBT center and had joined a gay men's comingout group at the center, too. He found the coming-out group to be especially helpful, as he was surrounded by peers who were navigating similar challenges. Most importantly, he felt unconditional support from the group members, who made Adam feel welcome and comfortable. Adam said that he was feeling a growing sense of connection with the LGBT center, and was considering volunteering there one evening per week. He was also interested in the range of groups available at the center, and was surprised by the number of religiously-focused meetings. I praised Adam for immersing himself in the center, and shared my excitement with him for all of the opportunities available to him there.

In session \#35, Adam said that he had had a difficult week because he had been verbally assaulted by several homophobic people on the street. Adam had been walking with two other members after a meeting at the LGBT center, and three men approached them, calling them "fags" and "homos." Adam felt "paralyzed" and feared that the men were going to physically assault him and his friends. After continuous taunts, the men retreated. Adam and his two friends were all “shaken” by this incident. I empathized with Adam's feelings of fear and paralysis, and said that being verbally assaulted in such a way would be scary for anyone to go through.

Adam said that he felt "terrified" and also somewhat "ashamed" for being targeted in this attack. He wanted to be liked by "everyone," yet in this situation, he had been exposed to significant hatred. I shared with Adam that despite his residing in a predominantly liberal, gayfriendly city, there were inevitably going to be some people with homophobic views; this harassment he experienced was a reflection of an external, societal problem, and did not indicate that the problem resided within him. Adam agreed with my statement, and said that when he spoke with his friends after the verbal assault took place, he recognized that the men were ignorant people who should not have the ability to affect his own sense of worth as a gay man. Adam said that this event had actually instilled in him a desire to become active in increasing gay rights in order to reduce the bigotry that he was exposed to that day.

I praised Adam for his handling of and reaction to the harassment incident; he had coped with a highly stressful situation by remaining with his friends in order to help each other process what had happened and support each other through the shock of such discriminatory behavior. Adam said that since the event, he had felt more strongly about coming out to his friends from college in order to stop living "separate lives:” his "straight” life while at his university dorm, and his "gay" life when he spent time with Jesse or anyone from the LGBT center. Adam said that his sister was also planning to visit him the following week, and he was thinking about coming out to her at that time. Adam said he was now "ready" to disclose his sexual identity to his friends and his sister, and he wanted my help in doing so.

Throughout my work with Adam, I consistently sought to uncover and manage my own biases. From the start of our treatment, I noticed myself having the desire for Adam to come out to safe people in his life. Part of this wish was based on my hypothesis that by coming out, Adam would have real-world data to refute his notion that he would be rejected by all people if 
he were gay. I also hypothesized that his coming out could serve to reduce his maladaptive belief that being gay means that he was "defective" and "abnormal." I realized, with the help of my supervisor, that the reason Adam had not yet come out or been more more active in the gay community was because he had not yet been ready to do so; I needed to be accepting of his journey and whatever outcome lay ahead of him. I also had to remind myself that an affirmative treatment approach is supportive of clients' unique identity development and whatever outcome clients choose in terms of how to outwardly identify. Continuously checking in with my personal and political biases helped me stay aware of how to interact with Adam such that my own desires would not negatively impact his treatment.

So when Adam shared in session \#35 that he was now ready to come out to his college friends and sister, I checked in with my own reaction. Just as Adam was excited about the prospect of sharing his orientation, I too, felt excited. Yet mixed in with my excitement were also feelings of apprehension. First, our therapy was coming to an end in only slightly over a month as I was slated to begin my new practicum placement, and would be terminating therapy with all of my patients at the Counseling Center. Would Adam have the support he needed as he started to navigate the coming-out process if he transitioned out of individual therapy at the same time? Second, I had concerns about Adam coming out to his sister. Although I suspected that she would respond positively to his disclosure, I was not so certain that Adam's parents would be as accepting of their son's gay identity. Adam was still financially reliant on his parents, as they were providing him with a college education, housing, and an allowance. If his parents were to find out about his gay identity via Adam's sister, highly negative consequences were possible, such as his parents disowning him and refusing to support him and his educational endeavors. Would Adam's sister be able to keep his gay identity a secret from their parents?

I told Adam that I was very excited and happy for him that he felt ready to tell important people in his life about his sexual orientation. I also shared with him that we needed to make sure that he came out safely and did not underestimate the potential consequences. I asked Adam: What were the costs and benefits of coming out to his friends at his university? Why did he want to come out to these friends, in particular? What were the costs and benefits of coming out to his sister? How did he plan to come out to his friends and to his sister?

Adam said that he planned to come out to two of his close college friends who were also in the dorm with him that summer. He said that both friends were open, nonjudgmental people, and had never evidenced any homophobic beliefs, at least in his presence. In addition, one of them already had a friend who was gay. Adam expected their reactions to his disclosure to be one of surprise, but also of support. Adam wanted to tell his sister that he was gay because he considered her his "best friend." She had been a source of constant support throughout his life, and he imagined that she would handle his disclosure in kind. I asked Adam if he wanted his sister to keep his disclosure hidden from his family and friends back at home. He replied that he would ask her to keep the fact that he was gay secret until he told her otherwise, as he could imagine his father feeling "betrayed," "humiliated,” and “furious” if he learned of his son's sexual orientation. Adam thought that there was the possibility that his father would try to force him into receiving conversion or reparative therapy to "convert" Adam to a heterosexual orientation. Despite his many fears about his father learning about his sexual orientation, Adam 
trusted that his sister would be able to keep this information private, as he had confided many things to her in the past and she always proved to be a safe confidant.

In order to help Adam prepare for the disclosures, we role-played his coming out to his friends and his sister. Adam decided that he would come out to each of his friends individually, and be direct and to the point in telling them that he was gay. He evidenced the same approach in his role-play with his sister, but also emphasized his need for her to keep the information private from their parents and friends back home, as he was not yet ready to disclose his sexuality to anyone else from their community. I commended Adam for his role-plays, in which he presented himself with poise and confidence.

In session \#36, Adam said that he had successfully come out to his college friends and his sister, and was feeling "very relieved" and "excited" about the support he received from them. Adam was especially moved by his sister's reaction. She started crying when Adam came out to her; she said that she had long suspected that he was gay, and was "so happy" that he was finally able to tell her. His sister hugged him and told Adam that she loved him, and promised to keep his identity a secret if that was what he wanted. Adam was surprised that his sister had wondered about him being gay, but said that it also made him feel even closer with her since she understood him even more than he had realized.

Adam said that he was now ready to be officially "out of the closet," and would continue to come out to his college friends as he saw them when the time seemed right. Come the beginning of his sophomore year of college, which was only two months away, he would come out as openly gay and no longer hide his identity. Although he was concerned about living a "double life," Adam decided that he would remain "straight" when he visited his family, at least for the time being. He feared that the consequences of coming out to his parents would be too grave, and therefore decided to embrace independence from his family by creating a life for himself in his university's city. I supported Adam's decision to delay telling his parents about his sexuality. I said that it made sense to me that he wanted to choose supportive people to come out to right now.

I told Adam that as he continued to come out at his university, it was likely that most people would show support, yet there was the possibility that not all people would be accepting. I asked Adam, “How do you see yourself handling that situation, if it were to arise?” Adam said that it would be hard for him if people were not accepting of his coming out, and added that external validation is something that he values, perhaps too strongly. After taking some time to ponder this hypothetical situation, Adam said that he would tell the person, "I'm sorry you feel that way, but this is who I am. I hope that you can ultimately accept that.” I told Adam that his response was excellent. It was firm, confident, and honest, but also left the person with the opportunity to change their views regarding Adam's sexual orientation. Adam said that if he needed support after a difficult disclosure, he could call Jesse or one of his friends from the LGBT center - or even attend a meeting there. I praised Adam for his idea of using social supports when he needed them most.

In session \#37, Adam shared that he had decided to attend a religion meeting at the LGBT center the previous week. Adam said that since beginning at MA, he had been thinking 
more about his feelings toward God, and had started to remember many of the positive aspects of his religion. At MA, he was able to think about a higher power as accepting and loving, and supporting Adam's strength to stay sober and make healthy life choices. Adam said that the religion meeting at the LGBT center proved to be "really interesting” because he was surrounded by people who identified as both LGBT and religious. Up until that moment, Adam had not realized that he could be both gay and a believer in God. Adam also learned that there were other LGBT Catholics who struggled with their religious identity. In the LGBT meeting, a group member referred to herself as a "recovering Catholic;" although she no longer identified as Catholic (since she felt mistreated by the Catholic community due to her nonheterosexual orientation), she still believed in her own God. Adam said that it was comforting to know that other "recovering Catholics" were able to maintain their ties to their God, despite being rejected from their initial religious communities.

Adam expressed both sadness and anger regarding Catholicism's view of sexual minorities; he had enjoyed being a part of his church's community while growing up, yet now he would not be accepted there because he was gay. He wished that he could still turn to his religious community from back home, and felt a sense of loss that he would not be able to do so as his "true self." Adam said that his church members would all believe that he was "doomed to burn in hell.” I asked Adam, “Doesn't your religion also hold the value to 'love your neighbor as yourself'? It seems to me that the church members aren't holding that value sacred if they are condemning you to hell based upon the very nature of who you are.” I shared with Adam that an increasing number of religious groups were becoming inclusive of all sexual orientations, and if he longed for a gay-friendly religious community that shared in his values, it would be possible for him to seek that out. I told him that the Unitarian Universalists and the Metropolitan Community Church were both inclusive, and that another religious group, called Dignity USA, had been created especially for LGBT individuals who were raised Catholic. I explained that in addition to providing Catholic LGBT individuals with support and a community in which to practice their Catholicism, Dignity USA also offers advocacy opportunities.

I suggested that Adam investigate these religious groups for homework. I said that his religious beliefs appeared to be of great value to him, as was his sexual identity, and that he did not need to choose one over the other. Adam said that since attending the LGBT religion meeting, he was feeling excited to continue his spiritual journey.

Toward the end of session \#37, I reminded Adam that we would only be meeting three more times, and I wanted us to make space over our last few sessions to reflect upon our work together. I asked Adam if he had considered whether he wanted to continue therapy with another clinician once our treatment ended. Adam said that he felt emotionally stable, and was no longer depressed or using marijuana. He said that based upon his improvements over the past year, he did not think that he needed to continue with therapy. I agreed with Adam that he had made enormous strides, but I wondered aloud if it would be helpful to continue seeing a therapist as he navigated coming out to all of his classmates in just a couple of months. I said that it could be useful to have extra support during that time. In order to promote his autonomy, I shared with Adam that the choice was entirely up to him whether to continue with treatment. Adam said that he would consider it over the next week as part of his homework; we could then revisit the issue in our next session. 


\section{Phase 5: Consolidating Gains and Termination}

Sessions 38 - 40: Reflecting on Therapeutic Gains, Relapse Prevention, and Termination

I had several goals for this final stage of treatment. First, I wanted to offer Adam the space to reflect upon his progress over the previous ten months. Second, I hoped to solidify his relapse prevention skills with regard to his depression and substance use. Third, I aimed to help Adam reflect upon his sexual identity development. Finally, I wanted Adam to process the fact that our therapeutic relationship was coming to an end.

From the beginning, Adam was aware that our treatment was time-limited given that I was completing a one-year training program as a part of my doctoral degree. Throughout the therapy I reminded Adam of this fact in order to prepare him (and me) for our upcoming termination. Under ideal circumstances, I believe it would have been beneficial for me to have continued working with Adam, at least until he had "officially" come out to his classmates at the beginning of his sophomore year of college. Although he had made enormous gains with regard to his sexual identity development over the previous year, I remembered that his plan to come out at the beginning of his freshman year had been so overwhelming to him that it appeared to precipitate a depressive episode and problematic substance use behaviors. Therefore, I imagined that Adam could benefit from having extra therapeutic support when he came out in the fall.

In session \#38, Adam said that he had considered my perspective, and decided that he would like to continue seeing a therapist at least through the beginning of his sophomore year of college. Adam said that for the first time in his life, he felt "free" - free from his depression, free from his reliance on marijuana, and free from his previous, negative view of himself. Yet despite being in a stable place, he recognized that coming out to his classmates and living as an openly gay man in this city would be a significant shift for him, and that it could be helpful to continue with therapy during that transition. I told Adam that I would arrange for a referral for him so that he could begin therapy with someone in a few weeks time.

I asked Adam, "What tools can you turn to if you notice a depressed mood emerging or strong urges to smoke pot?” My goal in asking Adam this question was for him to summarize and consolidate his learning and also increase his sense of self-efficacy to maintain his mental health. Adam listed off various coping skills that he had gained over the course of our therapy, including staying active, avoiding isolation, challenging maladaptive thoughts with the Dysfunctional Thought Record, attending MA meetings, reaching out to his sponsor, and practicing mindfulness skills. Adam also shared that his involvement at the LGBT center was a great source of support for him; reaching out to the gay community made him feel a sense of belonging and normalcy. I told Adam that I was delighted that he had gained all of this knowledge and had a plan of action for how to care for himself, independently. I reminded him, however, that if there was ever a time that his depression or substance use reemerged in the future when he was not in treatment and he was having difficulty coping on his own, he could always return to therapy for a "booster session."

In session \#39, I asked Adam what it was like for him to work with me. Did he have certain expectations about what therapy would be like? Did our therapy meet those 
expectations? Were there any points in the treatment that he felt disappointed in me? Were there any parts about our relationship that were helpful to him? Adam shared that initially, it had been difficult for him to feel comfortable talking openly about himself, and he felt "somewhat scared" to open up to me. He worried that I would view him as "annoying." Yet when we started working together, he quickly learned that our therapy was the place to uncover all of his thoughts and feelings, and that I would not judge him negatively.

In our last session (\#40), Adam and I reflected on and celebrated his gains in treatment, including his significant reduction in depressed mood, abstinence from marijuana, strong school performance and attendance, growing social network, and his more recent acceptance, and embrace, of his sexual identity. Much of this information is presented in greater detail in Chapter VIII, where I review Adam’s quantitative and qualitative assessment outcomes.

In order to assess Adam's internalized homophobic beliefs one last time, I asked him, "What do you think your chance of happiness is as a gay man?" He replied that he now believed that he could live a satisfying, happy life as a gay man, and much of that could be attributed to his connection to the gay community. I highlighted for Adam what a stark difference in perspective this was for him, for at the beginning of treatment, he had attached an enormous amount of stigma to his sexual identity. I commended Adam for his hard work and perseverance in treatment, which had led him to feelings of self-worth and excitement about his future.

Adam said that he still worried about his parents and how to navigate his sexual identity with them, but that he was becoming more comfortable with creating a life for himself in his new city. I noted to myself that at the beginning of treatment, Adam had presented as ingratiating and very eager to be liked by me and everyone else. It appeared that Adam's need for approval was starting to give way (e.g., he was willing to separate from his family in order to take care of his own needs), which I viewed as a positive sign that he was becoming more comfortable with his sense of self.

Adam said that he was sad to end therapy with me, but was also proud of the work he had done and how far he had come from when we first began working together. I shared with Adam that working with him had been a wonderful gift for me, that I would miss him very much, and think of him often. When I asked him how he wanted to say goodbye, Adam asked if it would be okay for us to hug. When I hugged Adam goodbye, I told him that I wished him all of the best in his future, and that I was so glad that we had been able to work together.

\section{THERAPY MONITORING AND USE OF FEEDBACK INFORMATION}

Throughout Adam’s treatment, I received individual supervision from a licensed, clinical psychologist. Each week before our supervision meeting, my supervisor would review the audio recording of my session with Adam. Our supervision was collaborative and active, and served to both challenge and support my clinical skills as a psychologist-in-training. In addition, the Counseling Center provided group supervision for its interns and externs, and was facilitated by two other licensed, clinical psychologists. The intensive combination of individual, group, and 
peer supervision provided me with excellent guidance and critical feedback during my work with Adam.

Adam's therapy was also continuously assessed via three quantitative self-report measures: the Beck Depression Inventory - Second Version (BDI-II); the Outcome Questionnaire - 45 (OQ-45); and the Internalized Homophobia Scale (IHP). Adam completed each of these measures directly before our therapy sessions on a biweekly basis from session \#4 onward. These three measures provided me and my supervisor with consistent feedback, and helped us gauge Adam's progress, or lack thereof, in treatment. In addition, the measures provided me with the ability to convey Adam's treatment status to him in a direct, objective manner. Finally, the simple act of completing these measures likely served to enhance Adam's self-awareness.

\section{CONCLUDING EVALUATION OF THE THERAPY'S PROCESS AND OUTCOME}

\section{The Outcome of Adam's Therapy}

The quantitative and qualitative data (see below) from Adam's case indicate a favorable treatment outcome. I believe that Adam's determination to "do therapy right" and his willingness to form a strong rapport with me played a formidable role in his ability to attain significant therapeutic gains by treatment termination.

\section{Quantitative Results}

Table 1 presents Adam's BDI-II scores. His initial scores were indicative of moderate depressive symptoms (as categorized by scores of 20-28, inclusive, on the BDI-II). Over the course of treatment, Adam's BDI-II scores decreased to the minimal depressive symptom range (as categorized by scores of $0-13$, inclusive, on the BDI-II).

Table 2 presents Adam's OQ-45 scores. His initial scores on the Total, Symptom Distress, Interpersonal Relations, and Social Role scales were all above the clinical cut-off points. By treatment termination, he scored below the clinical cut-off point on all four of the scales. The degree to which Adam's OQ-45 scores decreased points to a clinically significant reduction in symptoms associated with depression and school adjustment. In fact, his Total score decreased to a degree that far exceeded statistical significance, as measured by Jacobson and Truax's (1991) Reliable Change Index. Of note, however, is that although Adam's Interpersonal Relations subscale score decreased to below the clinical cut-off, his initial and final scores on this scale did not indicate a clinically significant "reliable change" (Lambert, Morton, Hatfield, Harmon, Hamilton, Reid, Shimokawa, Christopherson, \& Burlingame, 2004). Even though Adam noted a decrease in feelings of loneliness on the OQ-45, he continued to provide high scores (indicating dissatisfaction) for queries that targeted fulfillment in romantic relationships.

Table 3 presents Adam's IHP scores. The possible range of scores on the IHP is $9-45$, with 9 indicating no internalized homophobia, and 45 indicating extreme internalized homophobia. In a sample of 75 gay men recruited at an LGB street fair in Sacramento, 
California, the mean IHP score was 14.79 (Herek et al., 1997). At the start of treatment, Adam evidenced high internalized homophobia with a score of 40 . Starting at the mid-point of his therapy, Adam's internalized homophobia scores steadily decreased to a final score of 16, reflecting low internalized homophobia. In the context of Herek et al.'s (1997) study, Adam's change in IHP score from 40 (near the absolute top of the scale) to a score of 16 (near the absolute bottom of the scale) seems highly clinically significant, as his final IHP score approached the mean of the sample of openly gay men.

\section{Qualitative Results}

As described in Chapter VI (Course of Treatment), Adam and I reviewed his treatment gains during the last three sessions of his therapy. The following reflects a summary of the qualitative results of Adam's treatment outcome:

- Adam was no longer struggling with symptoms of depression that included depressed mood, anhedonia, decreased energy, difficulty concentrating, suicidal ideation, and feelings of guilt and worthlessness. He had learned how to challenge his negative core belief of himself as “defective” and "abnormal," and spoke of accepting his differentness. By treatment termination, Adam experienced many joys in his daily living and feelings of hope regarding his future.

- Adam had abstained from using marijuana for approximately five months. Over the course of treatment he identified and utilized alternative forms of coping with difficult thoughts and feelings, such as cognitive restructuring, relaxation, and mindfulness techniques. Adam also no longer viewed himself as "weird” for abstaining from smoking marijuana.

- By treatment termination, Adam was attending all of his university courses and consistently completed his homework assignments. Although over the course of treatment Adam resumed his demanding study habits that had earned him excellent grades in high school, he gained self-awareness regarding his perfectionistic academic strivings, which he realized were propelled by his wish to be a "perfect son" in order to “compensate" for being gay. Adam learned to moderate his typically strict study routine in order to allow himself time to socialize with friends, practice relaxation exercises, and engage in other pleasurable activities, such as playing the guitar.

- Adam was no longer avoiding interpersonal contact and had established many close friendships with peers at his university, MA, and at the LGBT center. He reported increased feelings of belonging, felt accepted as his "true self," and no longer struggled with intense feelings of loneliness.

- Adam was more able to advocate for his own needs. Even though his parents pressured him to return home for summer break, Adam had decided to stay in his university's city over the summer months in order to complete an internship. His growing ability to individuate from his parents provided him with the space to discover and accept himself with greater ease. Adam's increased self-confidence was also evident within our 
therapeutic relationship. Whereas at the start of treatment, he presented as highly ingratiating and invested in my total approval of him, by treatment termination he had demonstrated the ability to question my therapeutic interventions and even to disagree with me. I interpreted this behavior as a positive sign of increased assertiveness skills, as Adam had learned to voice his own wants in an effective manner.

- Adam had achieved a greater awareness of his internalized homophobia and learned how to identify and challenge his prejudicial beliefs. He was able to move through his fear by becoming an active member of the gay community at the LGBT center and safely began the coming-out process with supportive people in his life. Adam grew to accept himself as a gay man, and experienced sentiments of pride regarding his sexual identity. He felt a newfound sense of freedom in his ability to authentically relate to important others in his life.

- Adam realized that he could identify as both a gay man and a believer in God, and by treatment termination was beginning to integrate his sexual and religious identities.

\section{Results in Context of the Original Treatment Plan}

Based upon the quantitative and qualitative results listed above, it appears that Adam was able to meet all of the treatment goals that were described in Section 5, the "Case Formulation and Treatment Plan”:

GOAL 1: Provide rationale for treatment, establish rapport, and create a safe/validating therapeutic environment.

GOAL 2: To decrease Adam’s depressive symptoms to a BDI-II score in the absent to minimal range.

GOAL 3: To decrease Adam’s marijuana use.

GOAL 4: To increase Adam’s class attendance and completion of class assignments.

GOAL 5: To increase Adam's awareness of his internalized homophobia.

GOAL 6: To increase Adam's acceptance of his gay identity and decrease his IHP score to the low range.

GOAL 7: To decrease Adam's distress level to an OQ-45 score in the "less than clinical significance” range.

GOAL 8: To facilitate Adam’s reflection on therapeutic gains and provide relapse prevention skills.

GOAL 9: To provide Adam with the space to process treatment termination.

In summary, Adam experienced many changes over the course of our treatment together. His depressive symptoms decreased, he was no longer smoking marijuana, and he demonstrated strong school performance and attendance. Additionally, he uncovered his internalized homophobic beliefs and replaced them with feelings of worth, acceptance, and a sense of belonging. His eventual engagement with the LGBT community, despite his original fear to do 
so, appeared to facilitate his acceptance of his gay identity. His overall distress level decreased and he reported feelings of contentment and hopefulness about his future. Adam was also willing to form a strong therapeutic relationship with me, and over time, evidenced a growing ability to assert his own needs more directly and effectively.

\section{Discussion of Broader Issues Raised by Adam's Case}

I hope that this study sheds light upon some of the clinical situations that may arise when working with LGB clients who are struggling with significant internalized homophobia. However, as Adam is representative of only one individual within the sexual minority population, his case is not intended to generalize to all LGB individuals.

There are many advantages to employing hybrid-based case studies. Importantly, composite case examples inherently serve to disguise individual clients' presentations, and thus protect patient confidentiality. Additionally, creating a composite-case allowed me to highlight what I saw to be key clinical issues that emerged across my psychotherapy treatment with LGB clients. By demonstrating the real-world experiences of my various patients and corresponding treatment interventions, the composite case of Adam builds upon the existing knowledge base of treatment practices with sexual minority clients.

Despite the benefits, there are also limitations to a hybrid case study research format. For example, although the case material reflects the real life experiences of clients, the phenomenological experience of each individual client is lost in composite case studies. An alternative approach to studying clinical interventions with clients who struggle with significant internalized homophobia could include a single case design, wherein only one client's course of treatment would be investigated and documented in full at one time.

Although Adam's case can be used as a "best practice” resource for clinicians who work with sexual minority patients, I also hope that the study demonstrates some of the real clinical challenges that can emerge in therapy. I struggled with several issues during Adam's treatment, including his initial reluctance to address his sexual orientation, my own biases regarding my wanting him to come out, and my concern about his coming out directly preceding our termination. Deciding the appropriate course of action is not always easy to do on one's own, and points to the necessity of ample supervision and self-reflection.

As the political landscape in the United States is starting to shift its view of sexual minorities (e.g., by legalizing same-sex marriage on a state-by-state basis), perhaps internalized homophobic beliefs will decline. Yet despite these positive changes, LGBs continue to experience discrimination and unequal status as compared to their heterosexual counterparts. For example, same-sex marriage is not legally recognized throughout most of the United States. Additionally, it appears that incidences of antigay violence are on the rise (Goodman, 2013). Clearly, there is a long way to go before LGBs will be able to reside in an environment of equality and acceptance. Addressing the mental health needs of this at-risk population remains a relevant and important topic; therefore, clinically-oriented research should continue to investigate how best to serve the psychological well-being of sexual minorities. 


\section{REFERENCES}

American Psychiatric Association: Diagnostic and Statistical Manual of Mental Disorders, Fourth Edition, Text Revision. Washington, DC, American Psychiatric Association, 2000.

American Psychological Association. (2009). Report of the Task Force on Appropriate Therapeutic Responses to Sexual Orientation. Washington, DC: American Psychological Association.

American Psychological Association. (2012). Guidelines for psychological practice with lesbian, gay, and bisexual clients. American Psychologist, 67(1), 10-42.

Balsam, K.F., Huang, B., Fieland, K.C., Simoni, J.M., \& Walters, K.L. (2004). Culture, Trauma, and Wellness: A comparison of heterosexual and lesbian, gay, bisexual and two-spirit Native Americans. Cultural Diversity and Ethnic Minority Psychology, 10(3), 287-301.

Barlow, R. (2013, April 11). Gay parents as good as straight ones. BU Today. Retrieved from http://www.bu.edu/today/2013/gay-parents-as-good-as-straight-ones/

Beck, J.S. (1995). Cognitive therapy basics and beyond. New York, NY: The Guilford Press.

Beck, A.T., Steer, R.A., \& Brown, G.K. (1996). Manual for the Beck Depression Inventory-II. San Antonio, TX: Psychological Corporation.

Beckstead, L., \& Israel, T. (2010). Affirmative counseling and psychotherapy focused on issues related to sexual orientation conflicts. In K.J. Bieschke, R.M. Perez, \& K.A. DeBord (Eds.), Handbook of counseling and psychotherapy with lesbian, gay, bisexual, and transgender clients ( $2^{\text {nd }}$ ed.) (pp. 221-244). Washington, DC: American Psychological Association.

Bidell, M.P. (2005). The sexual orientation counselor competency scale: Assessing attitudes, skills, and knowledge of counselors working with lesbian, gay, and bisexual clients. Counselor Education \& Supervision, 44, 267-279.

Bowers, A.M.V., \& Bieschke, K.J. (2005). Psychologists' clinical evaluations and attitudes: An examination of the influence of gender and sexual orientation. Professional Psychology: Research and Practice, 36(1), 97-103.

Cass, V.C. (1979). Homosexual identity formation: A theoretical model. Journal of Homosexuality, 4(3), 219-235.

Cochran, S.D., Sullivan, J.G., \& Mays, V.M. (2003). Prevalence of mental disorders, psychological distress, and mental health services use among lesbian, gay, and bisexual adults in the United States. Journal of Consulting and Clinical Psychology, 71(1), 53-61.

Cohen, K.M., \& Savin-Williams, R.C. (2012). Coming out to self and others: Developmental milestone. In P. Levounis, J. Drescher, \& M.E. Barber (Eds.), The LGBT Casebook (pp. 17-33). Arlington, VA: American Psychiatric Publishing.

Coker, T.R., Austin, S.B., \& Schuster, M.A. (2010). The health and health care of lesbian, gay, and bisexual adolescents. Annual Review of Public Health, 31, 457-477.

Denning, P., \& Little, J. (2012). Practicing harm reduction psychotherapy: An alternative approach to addictions ( ${ }^{\text {nd }}$ ed.). New York, NY: The Guilford Press.

Dooley, J. (2009). Negotiating stigma: Lessons from the life stories of gay men. Journal of Gay \& Lesbian Social Services, 21, 13-29.

Drescher, J. (2012). What's in your closet? In P. Levounis, J. Drescher, \& M.E. Barber (Eds.), The LGBT Casebook (pp. 3-16). Arlington, VA: American Psychiatric Publishing.

Dworkin, S.H. (2001). Treating the bisexual client. Journal of Clinical Psychology, 57(5), 671- 
680.

Fassinger, R.E. (1991). The hidden minority: Issues and challenges in working with lesbian women and gay men. The Counseling Psychologist, 19(2), 157-176.

Fassinger, R.E., \& Richie, B.S. (1997). Sex matters: Gender and sexual orientation in training for multicultural counseling competency. In D.B. Pope-Davis, \& H.L.K. Coleman (Eds.), Multicultural counseling competencies: Assessment, education and training, and supervision (pp. 83-110). Thousand Oaks, California: Sage Publications.

Fishman, D.B. (1999). The case for pragmatic psychology. New York, NY: New York University Press.

Garnets, L., Hancock, K.A., Cochran, S.D., Goodchilds, J., \& Peplau, L.A. (1991). Issues in psychotherapy with lesbians and gay men: A survey of psychologists. American Psychologist, 46(9), 964-972.

Glassgold, J.M. (2009). The case of Felix: An example of gay-affirmative, cognitive-behavioral therapy. Pragmatic Case Studies in Psychotherapy, 5(4), Article 1, 1-21. Available: http://hdl.rutgers.edu/1782.1/pcsp_journal

Goodman, J.D. (2013, May 21). Two more antigay attacks are reported in Manhattan. The New York Times. Retrieved from http://www.nytimes.com

Hays, P.A. (1996). Addressing the complexities of culture and gender in counseling. Journal of Counseling \& Development, 74(4), 332-338.

Hays, P.A. (2009). Integrating evidence-based practice, cognitive-behavior therapy, and multicultural therapy: Ten steps for culturally competent practice. Professional Psychology: Research and Practice, 40(4), 354-360.

Hayes, S.C. (2004). Acceptance and commitment therapy, relational frame theory, and the third wave of behavioral and cognitive therapies. Behavior Therapy, 35 (4), 639-665.

Hayes, S.C., \& Smith, S. (2005). Get out of your mind and into your life. Oakland, CA: New Harbinger Publications.

Herek, G.M. (2004). Beyond "homophobia": Thinking about sexual prejudice and stigma in the twenty-first century. Sexuality Research \& Social Policy, 1(2), 6-24.

Herek, G.M. (2007). Confronting sexual stigma and prejudice: Theory and practice. Journal of Social Issues, 63(4), 905-925.

Herek, G.M. (2010). Sexual orientation differences as deficits: Science and stigma in the history of American psychology. Perspectives on Psychological Science, 5(6), 693-699.

Herek, G.M., Cogan, J.C., Gillis, J.R., \& Glunt, E.K. (1997). Correlates of internalized homophobia in a community sample of lesbians and gay men. Journal of the Gay and Lesbian Medical Association, 2, 17-25.

Herek, G.M., Gillis, J.R., \& Cogan, J.C. (2009). Internalized stigma among sexual minority adults: Insights from a social psychological perspective. Journal of Counseling Psychology, 56(1), 32-43.

Hooker, E.A. (1957). The adjustment of the male overt homosexual. Journal of Projective Techniques, 21, 18-31.

Igartua, K.J. (2012). Doctor, am I gay? Identity problems associated with homoerotism. In P. Levounis, J. Drescher, \& M.E. Barber (Eds.), The LGBT Casebook (pp. 255-264). Arlington, VA: American Psychiatric Publishing.

Ilardi, S.S., \& Craighead, W.E. (1994). The role of nonspecific factors in cognitive-behavior therapy for depression. Clinical Psychology: Science \& Practice, 1, 138-156. 
Israel, T., \& Selvidge, M.M.D. (2003). Contributions of multicultural counseling tocounselor competence with lesbian, gay, and bisexual clients. Journal of Multicultural Counseling and Development, 31, 84-98.

Jacobson, N.S., \& Truax, P. (1991). Clinical significance: A statistical approach to defining meaningful change in psychotherapy research. Journal of Consulting andClinical Psychology, 59(1), 12-19.

Kantor, M. (2002). My guy: A gay man's guide to a lasting relationship. Naperville, IL: Sourcebooks.

Katz, J.N. (2001). Love stories: Sex between men before homosexuality. Chicago, IL: The University of Chicago Press.

Kinsey, A.C., Pomeroy, W.B., Martin, C.E., \& Gebhard, P. (1953). Sexual behavior in the human female. Philadelphia, PA: W.B. Saunders.

Lambert, M.J., Burlingame, G.M., Umphress, V., Hansen, N.B., Vermeersch, D.A., Clouse, G.C., \& Yanchar, S.C. (1996). The reliability and validity of the Outcome Questionnaire. Clinical Psychology \& Psychotherapy, 3(4), 249-258.

Lambert, M.J., Morton, J.J., Hatfield, D., Harmon, C., Hamilton, S., Reid, R.C., Shimokawa, K., Christopherson, C., \& Burlingame, G. B. (2004). Administration and scoring manual for the OQ-45.2 (Outcome Questionnaire). Orem, UT: American Professional Credentialing Services.

Levounis, P., Drescher, J., \& Barber, M.E. (2012). The LGBT casebook. Arlington, VA: American Psychiatric Publishing.

Lewis, R.J., Derlega, V.J., Griffin, J.L., \& Krowinski, A.C. (2003). Stressors for gay men and lesbians: Life stress, gay-related stress, stigma consciousness, and depressive symptoms. Journal of Social and Clinical Psychology, 22(6), 716-729.

Mandel, S. H. (2013). Targeting sexual stigma: The hybrid case study of "Adam." Unpublished doctoral dissertation, Rutgers University, Piscataway, NJ.

Martell, C.R., Safren, S.A., \& Prince, S.E. (2004). Cognitive-behavioral therapies with lesbian, gay, and bisexual clients. New York, NY: The Guilford Press.

Matthews, C.R. (2010). Affirmative lesbian, gay, and bisexual counseling with all clients. In K.J. Bieschke, R.M. Perez, \& K.A. DeBord (Eds.), Handbook of counseling and psychotherapy with lesbian, gay, bisexual, and transgender clients ( $2^{\text {nd }}$ ed.) (pp. 201219). Washington, DC: American Psychological Association.

McCrady, B.S. (2008). Alcohol use disorders. In D.H. Barlow (Ed.), Clinical handbook of psychological disorders (4 ${ }^{\text {th }}$ ed.) (pp. 492-546). New York, NY: The Guilford Press.

McWilliams, N. (1999). Psychoanalytic case formulation. New York, NY: The Guilford Press.

Meyer, E.J. (2010). Gender and sexual diversity in schools. New York, NY: Springer.

Meyer, I.H. (1995). Minority stress and mental health in gay men. Journal of Health and Sexual Behavior, 36, 38-56.

Miller, W.R., \& Rollnick, S. (2002). Motivational interviewing: Preparing people for change ( $2^{\text {nd }}$ ed.). New York, NY: The Guilford Press.

Mio, J.S., Barker-Hackett, L., \& Tumambing, J.S. (2009). Multicultural psychology: Understanding our diverse communities ( ${ }^{\text {nd }}$ ed.). New York, NY: McGraw-Hill.

Pachankis, J.E., \& Goldfried, M.R. (2004). Clinical issues in working with lesbian, gay, and bisexual clients. Psychotherapy: Theory, Research, Practice, Training. 41(3), $\quad 227-$ 246. 
Persons, J.B. (2008). The case formulation approach to cognitive-behavior therapy. New York, NY: The Guilford Press.

Peterson, D.R. (1996). Making psychology indispensable. Applied \& Preventive Psychology, 5, $1-8$.

Pizer, J.C. (2012). From outlaws to in-laws. In P. Levounis, J. Drescher, \& M.E. Barber (Eds.), The LGBT Casebook (pp. 35-58). Arlington, VA: American Psychiatric Publishing.

Pope, M. (1995). The "salad bowl” is big enough for us all: An argument for the inclusion of lesbians and gay men in any definition of multiculturalism. Journal of Counseling \& Development, 73, 301-304.

Ritter, K.Y., \& Terndrup, A.I. (2002). Handbook of affirmative psychotherapy with lesbians and gay men. New York, NY: The Guilford Press.

Rosario, M., Schrimshaw, E.W., \& Hunter, J. (2009). Disclosure of sexual orientation and subsequent substance use and abuse among lesbian, gay, and bisexual youths: Critical role of disclosure reactions. Psychology of Addictive Behaviors, 23(1), 175-184.

Safren, S.A., Hollander, G., Hart, T.A., \& Heimberg, R.G. (2001). Cognitive-behavioral therapy with lesbian, gay, and bisexual youth. Cognitive and Behavioral Practice, 215-223.

Schneider, M.S., Brown, L.S., \& Glassgold, J.M. (2002). Implementing the resolution on appropriate therapeutic responses to sexual orientation: A guide for the perplexed. Professional Psychology: Research and Practice, 33(3), 265-276.

Sue, D.W., Arredondo, P., \& McDavis, R.J. (1992). Multicultural counseling competencies and standards: A call to the profession. Journal of Multicultural Counseling \& Development, 20(2), 477-486.

Sue, S. (2006). Cultural competency: From philosophy to research and practice. Journal of Community Psychology, 34(2), 237-245.

Sue, D.W., \& Sue, D. (2013). Counseling the culturally diverse: Theory and practice ( $6^{\text {th }}$ ed.). Hoboken, NJ: John Wiley \& Sons.

Sulzberger, A.G. (2012, January 20). Kansas law on sodomy stays on books despite a cull. The New York Times. Retrieved from http://www.nytimes.com

Twohig, M.P., Shoenberger, D., \& Hayes, S.C. (2007). A preliminary investigation of acceptance and commitment therapy as a treatment for marijuana dependence in adults. Journal of Applied Behavior Analysis, 40(4), 619-632.

Young, J.E., Rygh, J.L., Weinberger, A.D., \& Beck, A.T. (2008). Cognitive therapy for depression. In D.H. Barlow (Ed.), Clinical handbook of psychological disorders ( $4^{\text {th }}$ ed.) (pp. 250-305). New York, NY: The Guilford Press. 
Table 1. Adam's Scores: Beck Depression Inventory - Second Version

\begin{tabular}{|c|c|l|}
\hline Session Number & Score & Score Categorization* \\
\hline \hline 4 & 27 & Moderate depression \\
\hline 6 & 28 & Moderate depression \\
\hline 8 & 20 & Moderate depression \\
\hline 10 & 16 & Mild depression \\
\hline 12 & 14 & Mild depression \\
\hline 14 & 15 & Mild depression \\
\hline 16 & 14 & Mild depression \\
\hline 18 & 12 & Minimal depression \\
\hline 20 & 12 & Minimal depression \\
\hline 22 & 14 & Mild depression \\
\hline 24 & 10 & Minimal depression \\
\hline 26 & 8 & Minimal depression \\
\hline 28 & 8 & Minimal depression \\
\hline 30 & 9 & Minimal depression \\
\hline 32 & 6 & Minimal depression \\
\hline 34 & 6 & Minimal depression \\
\hline 36 & 5 & Minimal depression \\
\hline 38 & 5 & Minimal depression \\
\hline 40 & 5 & Minimal depression \\
\hline & & \\
\hline
\end{tabular}

* Score categorization as noted by Beck, Steer, and Brown (1996) in the Manual for the Beck Depression Inventory - II. 
Table 2. Adam's Scores: Outcome Questionnaire - 45

\begin{tabular}{|c|c|c|c|c|}
\hline $\begin{array}{l}\text { Session } \\
\text { Number }\end{array}$ & Total Score+ & $\begin{array}{l}\text { Symptom } \\
\text { Distress Score+ }\end{array}$ & $\begin{array}{l}\text { Interpersonal } \\
\text { Relations } \\
\text { Score+ } \\
\end{array}$ & $\begin{array}{l}\text { Social Role } \\
\text { Score+ }\end{array}$ \\
\hline 4 & $89 \#$ & 48\# & $20 \#$ & 21\# \\
\hline 6 & $90 \#$ & $48 \#$ & 22\# & $20 \#$ \\
\hline 8 & 71\# & 34 & 20\# & $17 \#$ \\
\hline 10 & 74\# & 33 & 21\# & 20\# \\
\hline 12 & 59 & 25 & 20\# & $14 \#$ \\
\hline 14 & 60 & 25 & 23\# & $12 \#$ \\
\hline 16 & 57 & 23 & $22 \#$ & $12 \#$ \\
\hline 18 & 61 & 25 & 20\# & $16 \#$ \\
\hline 20 & 56 & 24 & 20\# & $12 \#$ \\
\hline 22 & $66 \#$ & 32 & 20\# & $14 \#$ \\
\hline 24 & 52 & 23 & $18 \#$ & 11 \\
\hline 26 & 47 & 22 & $18 \#$ & 7 \\
\hline 28 & 47 & 23 & $17 \#$ & 7 \\
\hline 30 & 46 & 24 & $16 \#$ & 6 \\
\hline 32 & 45 & 23 & $16 \#$ & 6 \\
\hline 34 & 47 & 22 & $17 \#$ & 8 \\
\hline 36 & 40 & 19 & $15 \#$ & 6 \\
\hline 38 & 41 & 20 & 14 & 7 \\
\hline 40 & $40 *$ & $20 *$ & 14 & 6* \\
\hline
\end{tabular}

\# Higher scores indicate symptoms and/or impaired functioning are above the clinical cut-off point as noted by Lambert, Morton, Hatfield, Harmon, Hamilton, Reid, Shimokawa, Christopherson, and Burlingame (2004) in the Administration and Scoring Manual for the OQ45.2 (Outcome Questionnaire).

+ Clinical cut-off scores are the following: Total Score of 63 or above; Symptom Distress Score of 36 or above; Interpersonal Relations Score of 15 or above; and Social Role Score of 12 or above (Lambert et al., 2004).

* Decrease between "Session 4" and "Session 40" scores statistically significant via Jacobson and Truax’s (1991) Reliable Change Index. 
Targeting Sexual Stigma: The Hybrid Case Study of "Adam"

S.H. Mandel

Pragmatic Case Studies in Psychotherapy, http://pcsp.libraries.rutgers.edu

Volume 10, Module 2, Article 1, pp. 48-105, 08-10-14 [copyright by author]

Table 3. Adam's Scores: Internalized Homophobia Scale

\begin{tabular}{|c|c|}
\hline Session Number & Score \\
\hline 4 & 40 \\
\hline 6 & 40 \\
\hline 8 & 40 \\
\hline 10 & 40 \\
\hline 12 & 41 \\
\hline 14 & 41 \\
\hline 16 & 40 \\
\hline 18 & 40 \\
\hline 20 & 40 \\
\hline 22 & 41 \\
\hline 24 & 39 \\
\hline 26 & 36 \\
\hline 28 & 30 \\
\hline 30 & 28 \\
\hline 32 & 23 \\
\hline 34 & 19 \\
\hline 36 & 17 \\
\hline 38 & 17 \\
\hline 40 & 16 \\
\hline
\end{tabular}


Table 4. Diagnosis at Beginning and End of Treatment

\begin{tabular}{|c|c|c|c|c|}
\hline \multirow[b]{2}{*}{ Axis I } & \multicolumn{2}{|c|}{$\begin{array}{l}\text { DSM-IV-TR Diagnosis at } \\
\text { Beginning of Therapy }\end{array}$} & \multicolumn{2}{|c|}{$\begin{array}{l}\text { DSM-IV-TR Diagnosis at End of } \\
\text { Therapy }\end{array}$} \\
\hline & $\begin{array}{l}296.22 \\
300.4 \\
304.30\end{array}$ & $\begin{array}{l}\text { Major } \\
\text { Depressive } \\
\text { Disorder, } \\
\text { Moderate, } \\
\text { Single Episode } \\
\text { Dysthymic } \\
\text { Disorder, Early } \\
\text { Onset } \\
\text { Cannabis } \\
\text { Dependence, } \\
\text { Without } \\
\text { Physiological } \\
\text { Dependence }\end{array}$ & $\begin{array}{l}296.26 \\
304.30\end{array}$ & $\begin{array}{l}\text { Major } \\
\text { Depressive } \\
\text { Disorder, } \\
\text { Single Episode, } \\
\text { In Full } \\
\text { Remission } \\
\\
\\
\text { Cannabis } \\
\text { Dependence, } \\
\text { Without } \\
\text { Physiological } \\
\text { Dependence, } \\
\text { Early Full } \\
\text { Remission }\end{array}$ \\
\hline Axis II & V71.09 & No diagnosis & V71.09 & No diagnosis \\
\hline Axis III & & None & & None \\
\hline Axis IV & & $\begin{array}{l}\text { Adjustment to } \\
\text { college, } \\
\text { academic } \\
\text { problems, } \\
\text { inadequate } \\
\text { social support, } \\
\text { familial stress }\end{array}$ & & Familial stress \\
\hline Axis $\mathrm{V}$ & & $\mathrm{GAF}=55$ & & $\mathrm{GAF}=79$ \\
\hline
\end{tabular}


Table 5. Gay Affirmative Treatment Interventions with Adam

\begin{tabular}{|c|c|}
\hline Uncovering Internalized Homophobia & Identity Acceptance Techniques \\
\hline Complete IHP form throughout treatment & $\begin{array}{l}\text { Dispel myths and stereotypes regarding sexual } \\
\text { minorities }\end{array}$ \\
\hline Free associate to word "gay” exercise & Reframe being gay as positive \\
\hline $\begin{array}{l}\text { Ask client how he views his attractions } \\
\text { (e.g., are they burdens, sinful, joyful?) }\end{array}$ & $\begin{array}{l}\text { Reframe attractions as natural and out of one's } \\
\text { control }\end{array}$ \\
\hline \multirow[t]{11}{*}{ Psychoeducation regarding cultural stigma } & $\begin{array}{l}\text { Mindfulness exercises to teach client to accept } \\
\text { attractions openly and nonjudgmentally }\end{array}$ \\
\hline & $\begin{array}{l}\text { Acknowledge and empathize with loss of client } \\
\text { never living the life of a privileged-status } \\
\text { heterosexual }\end{array}$ \\
\hline & $\begin{array}{l}\text { Bibliotherapy (i.e., direct client to LGB books and } \\
\text { articles relevant to presenting problem) }\end{array}$ \\
\hline & $\begin{array}{l}\text { Increase client's self-efficacy to become member of } \\
\text { the gay community }\end{array}$ \\
\hline & $\begin{array}{l}\text { Psychoeducation regarding the damaging effects of } \\
\text { gender scripts (i.e., cultural “guidelines” for } \\
\text { "appropriate” male behavior) }\end{array}$ \\
\hline & Challenge restrictive view of masculinity \\
\hline & Challenge "abnormal” and "defective” schemas \\
\hline & $\begin{array}{l}\text { Psychoeducation regarding client's ability to form } \\
\text { monogamous, life-long commitment with a partner } \\
\text { and create a family }\end{array}$ \\
\hline & Identify the costs and benefits of coming out \\
\hline & Practice coming out via role play exercises \\
\hline & $\begin{array}{l}\text { Educate client regarding LGB-friendly religious } \\
\text { institutions }\end{array}$ \\
\hline
\end{tabular}

